\title{
Impairment of Host Liver Repopulation by Transplanted Hepatocytes in Aged Rats and the Release by Short-Term Growth Hormone Treatment
}

\author{
Peggy Stock, ${ }^{*}$ Maximilian Bielohuby, ${ }^{\dagger}$ Martin S. Staege ${ }^{\ddagger}$ Mei-Ju Hsu, ${ }^{*}$ Martin Bidlingmaier, ${ }^{\dagger}$ and Bruno Christ*
}

\begin{abstract}
From the Division of Applied Molecular Hepatology, * Clinics and Policlinics of Visceral, Transplantation, Thoracic, and Vascular Surgery, University of Leipzig, Leipzig; the Endocrine Research Unit, ${ }^{\dagger}$ Department of Internal Medicine IV, Ludwig Maximilian University, Munich; and the Department of Pediatrics I, Martin Luther University Halle-Wittenberg, Halle, Germany
\end{abstract}

\author{
Accepted for publication \\ November 28, 2016. \\ Address correspondence \\ to Peggy Stock, Ph.D., Division \\ of Applied Molecular Hepatol- \\ ogy, Clinics and Policlinics of \\ Visceral, Transplantation, \\ Thoracic, and Vascular Sur- \\ gery, University of Leipzig, \\ Liebigstraße 21, D-04103 \\ Leipzig, Germany. E-mail: \\ peggy.stock@medizin.uni- \\ leipzig.de.
}

\begin{abstract}
Hepatocyte transplantation is an alternative to whole liver transplantation. Yet, efficient liver repopulation by transplanted hepatocytes is low in livers of old animals. This restraint might be because of the poor proliferative capacity of aged donor hepatocytes or the regenerative impairment of the recipient livers. The age-dependent liver repopulation by transplanted wild-type hepatocytes was investigated in juvenile and senescent rats deficient in dipeptidyl-peptidase IV. Repopulation was quantified by flow cytometry and histochemical estimation of dipeptidyl-peptidase IV enzyme activity of donor cells in the negative host liver. As a potential pathway involved, expression of cell cycle proteins was assessed. Irrespective of the age of the donor hepatocytes, large cell clusters appeared in juvenile, but only small clusters in senescent host livers. Because juvenile and senescent donor hepatocytes were likewise functional, host-derived factor(s) impaired senescent host liver repopulation. Growth hormone levels were significantly higher in juvenile than in senescent rats, suggesting that growth hormone might promote host liver repopulation. Indeed, short-term treatment with growth hormone augmented senescent host liver repopulation involving the growth hormone-mediated release of the transcriptional blockade of genes associated with cell cycle progression. Short-term growth hormone substitution might improve liver repopulation by transplanted hepatocytes, thus augmenting the therapeutic benefit of clinical hepatocyte transplantation in older patients. (Am J Pathol 2017, 187: 553-569; http://dx.doi.org/10.1016/j.ajpath.2016.11.016)
\end{abstract}

Orthotopic liver transplantation is still the gold standard therapy for patients with end-stage liver diseases or liverbased metabolic defects. ${ }^{1}$ Because donor shortage limits the number of patients receiving this life-saving treatment worldwide, hepatocyte transplantation was regarded a new therapeutic option. This method had several obvious advantages over orthotopic liver transplantation: hepatocytes isolated from one donor liver could be applied to several patients and only minimal invasive surgery is needed for hepatocyte transplantation. Moreover, cryopreservation allows for hepatocyte transplantation on demand with fewer complications because of graft failure and may bridge the time to orthotopic liver transplantation. ${ }^{2}$ Corroborating feasibility, the outcome of the first 100 patients receiving hepatocyte transplants was recently summarized. ${ }^{3}$ Nevertheless, the lack of significant therapeutic success still hampers the clinical breakthrough of hepatocyte transplantation. ${ }^{4}$ The major reason might be that only marginal livers are available for hepatocyte isolation, ${ }^{3}$ yielding hepatocytes with a poor liver repopulation efficiency after transplantation. This was likely because of the impairment of hepatocytes' proliferative capacity linked to the age of the liver donors, ${ }^{5}$ yet, without obvious functional impairment, because clinically relevant biochemical

\footnotetext{
Supported by Martin Luther University Halle-Wittenberg, Germany (FKZ14/38); and Ministry of Science and Technology, Taiwan Postdoctoral Research Abroad Program (105-2917-I-564-071; M.-J.H.).

Disclosures: None declared.

Current address of Max.B., R\&D Diabetes Division/Insulin Biology Cluster, Sanofi-Aventis Deutschland GmbH, Frankfurt am Main, Germany.
} 
parameters remained within the accepted reference ranges. ${ }^{6}$ In line, the suitability of senescent donor livers for orthotopic liver transplantation was reported.

The regenerative potential of the liver is well established and has been widely investigated in animal models with severe liver injury, including liver damage induced by partial hepatectomy. ${ }^{8}$ Several groups investigated the agerelated decline of the regenerative competence of the liver $^{9,10}$ and reported that low systemic growth hormone (GH) levels were associated with a reduced regenerative capacity. ${ }^{11,12}$ This could be because of the inhibition of cell cycle progression in aged livers, which was linked to epigenetic alterations due to low GH levels. ${ }^{13}$

Little is known about the molecular and cellular mechanisms underlying the integration of transplanted hepatocytes into the host parenchyma and the mechanisms of repopulation requiring active expulsion of host by the donor hepatocytes. ${ }^{14}$ Furthermore, preconditioning of the recipient liver by the antimitotic pyrrolizidine alkaloid retrorsine to increase repopulation led to hepatocyte senescence, and transplantation of a mixture of aged and juvenile hepatocytes yielded larger donor cell clusters derived from young as compared to the old donor cells, indicating the cellautonomous loss of proliferative competitiveness of aged hepatocytes. ${ }^{15,16}$ Studies addressing the cell cycle during age-dependent liver repopulation by transplanted hepatocytes are still missing.

Herein, we studied in a well-established rat model ${ }^{17}$ the relevance of the donor hepatocyte and the recipient liver age with respect to their functional and proliferative capacities. We demonstrated that the short-term treatment with growth hormone enhanced repopulation by transplanted hepatocytes in senescent host livers likely, at least in part, by the resolution of hepatocyte cell cycle arrest in the old livers.

\section{Materials and Methods}

Unless otherwise indicated, all chemicals were obtained from Sigma-Aldrich GmbH (Munich, Germany). Primary antibodies and their combination with the secondary antibodies as well as details for use are summarized in Table 1 .

\section{Animal Studies}

Male animals were kept under a 12-hour light/dark cycle with free access to food (1320; Altromin, Lage, Germany) and water. All animal experiments were performed in part in the barrier animal facility approved by the regulatory authorities of Halle, Germany, and the animal protection commissary of the University of Halle-Wittenberg (Halle, Germany).

\section{Isolation of Rat Hepatocytes}

Primary donor hepatocytes were isolated from either 4-weekold dipeptidyl-peptidase IV (DPPIV)-positive wild-type Fischer F344 rats (Charles River, Berlin, Germany) (80 to
$90 \mathrm{~g}$ ) to obtain juvenile hepatocytes or from over 12-monthold wild-type Fischer F344 rats ( 380 to $400 \mathrm{~g}$ ) by the two-step collagenase perfusion technique, according to Seglen ${ }^{18}$ and described in Stock. ${ }^{19}$ The final cell suspension was resuspended in phosphate-buffered saline (PBS), and aliquots of 5 $\times 10^{6}$ hepatocytes were stored on ice until transplantation. For cell culture, cells were plated on collagen-coated plastic dishes at a density of $3 \times 10^{5}$ cells per $\mathrm{mL}$ of minimal essential medium, which was replaced after 2 hours by hepatocyte growth medium containing epidermal growth factor and hepatocyte growth factor, as described, ${ }^{20}$ and changed every 24 hours. Cells were analyzed at each day for up to 8 days of culture.

\section{Transplantation of Hepatocytes into Livers of DPPIV-Deficient Fischer F344 Rats}

The model used in this study was previously established by Laconi et al. ${ }^{21}$ Host Fischer F344 rats show a natural mutation leading to deficiency for DPPIV,${ }^{17}$ allowing for the detection of wild-type donor hepatocytes in the negative host liver by the histochemical stain of DPPIV enzyme activity. Transplanted hepatocytes were provided with a growth advantage over host hepatocytes by i.p. treatment of the recipient rat with $30 \mathrm{mg} / \mathrm{kg}$ retrorsine 6 and 4 weeks before cell transplantation, starting in juvenile host rats at 4 weeks of age and in old animals at $>12$ months of age, as described. ${ }^{19}$ A mitotic stimulus was applied by one third partial hepatectomy. Donor hepatocytes isolated from either juvenile (4 weeks old) or senescent ( $>12$ months old) wild-type Fischer F344 rats, as described in the precedent paragraph, were transplanted into DPPIV-deficient Fischer F344 juvenile or old recipient rats, as summarized in Figure 1. Recipients were anesthetized with isoflurane (Forene; Abbott $\mathrm{GmbH}$, Wiesbaden, Germany), and the lateral segment of the left liver lobe was removed by central ligation (30\% hepatectomy). Thereafter, $5 \times 10^{6}$ hepatocytes were slowly injected into the portal vein over 3 minutes using a 28 gauge insulin syringe. Animals were sacrificed at 6 weeks after hepatocyte transplantation for quantification of repopulation efficiency by flow cytometry, or tissue samples from each liver lobe were snap frozen and stored for further analysis.

\section{Histochemical Detection of DPPIV and Costaining of Glycogen by the Periodic Acid-Schiff Reaction}

The enzymatic activity of the DPPIV hydrolyzes the substrate gly-pro-4-methoxy- $\beta$-naphtylamide to glycyl-proline and 4-methoxy- $\beta$-naphtylamide. Fast Blue is bound to the latter by forming a diazo-bond, which causes red coloring of DPPIV-positive cells.

The periodic acid-Schiff reaction was used to visualize glycogen storage within the hepatocytes. Polysaccharides are detected by oxidizing vicinal diols to aldehydes by periodic acid and using the Schiff's reagent to form purplemagenta color complexes. 
Table 1 List of Primary Antibodies Used in This Study Including Supplier, Dilution in Experiment, Secondary Antibodies, and Application in the Present Study

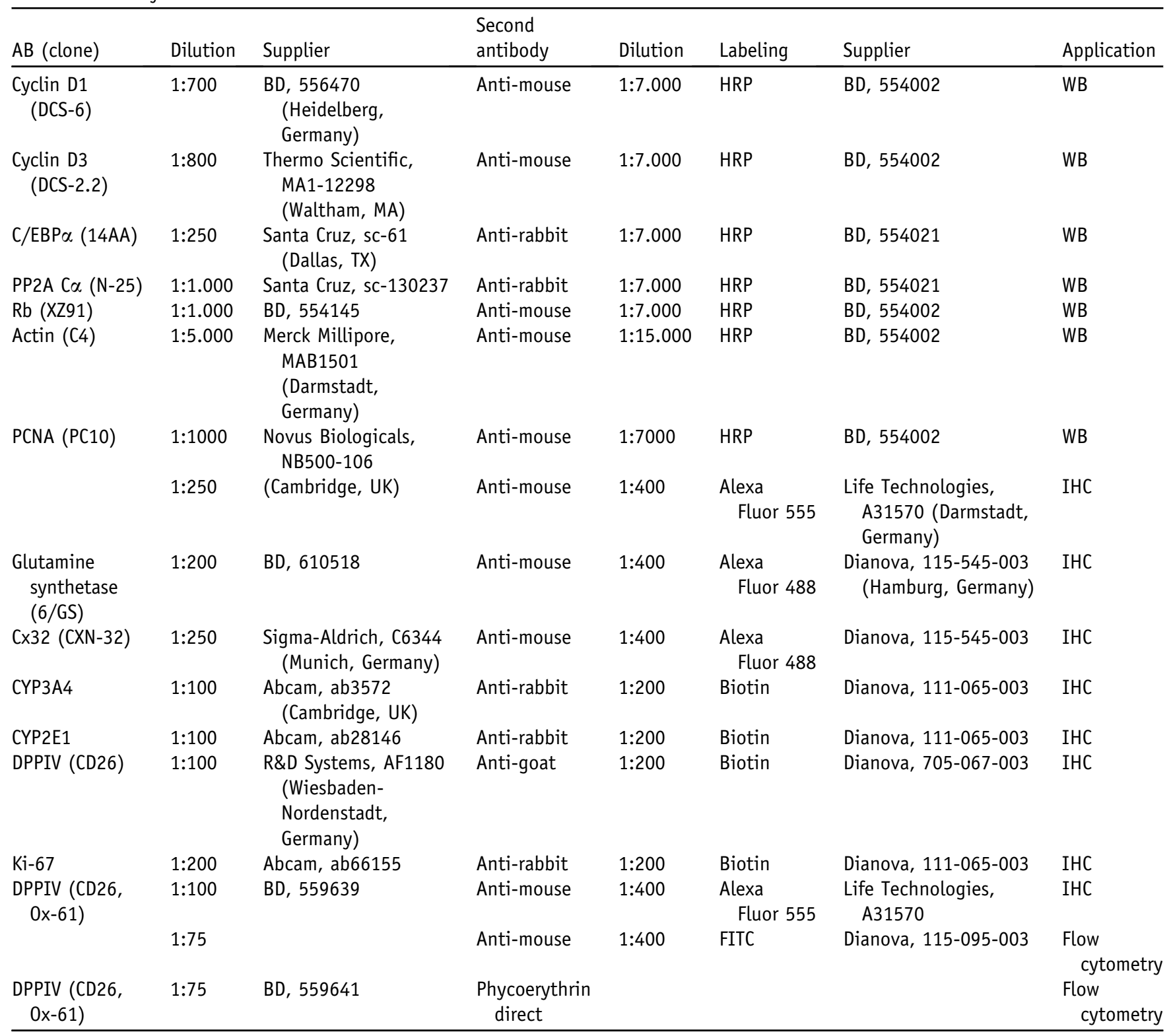

$\mathrm{AB}$, antibody; BD, Becton Dickinson; C/EBP $\alpha$, CCAAT/enhancer-binding protein $\alpha ;$ Cx32, connexin 32; CYP, cytochrome P450; DPPIV, dipeptidyl-peptidase IV; FITC, fluorescein isothiocyanate; HRP, horseradish peroxidase; IHC, immunohistochemistry; PCNA, proliferating cell nuclear antigen; PP2A, protein phosphatase $2 A ; R b$, retinoblastoma; $W B$, Western blot.

To detect DPPIV activity in donor cells, cryosections ( $5 \mu \mathrm{m}$ thick) of liver tissue were prepared by using the MEV cryostat (SLEE Technical GmbH, Mainz, Germany), costaining was performed as described in detail, ${ }^{19}$ and slides were analyzed by bright field microscopy (Eclipse E600, Nikon, Düsseldorf, Germany; Lucia G software, Nikon).

\section{Immunofluorescence Staining and Colocalization of DPPIV with $\mathrm{C} \times 32$ and Glutamine Synthetase}

Cryosections (5 $\mu \mathrm{m}$ thick) were fixed for 10 minutes at $4{ }^{\circ} \mathrm{C}$ in acetone, air dried, and washed three times for 5 minutes with $50 \mathrm{mmol} / \mathrm{L}$ Tris (pH 7.6). The slides were blocked with
5\% goat serum for 20 minutes at room temperature and incubated with the primary antibody [glutamine synthetase, 1:200, or connexin 32 (Cx32), 1:250, in Tris-HCl] overnight at $4^{\circ} \mathrm{C}$. Slides were washed, as described above, and incubated with the Alexa Fluor 488 anti-mouse secondary antibody (1:400) for 1 hour at room temperature. Slides were then washed as described. To colocalize DPPIV with Cx32 or glutamine synthetase, tissues were first immune stained for Cx32 or glutamine synthetase, blocked with mouse-onmouse blocking reagent from Vector Laboratories (Burlingame, CA), for 1 hour, washed as described, and subsequently incubated with the anti-DPPIV (1:100) antibody overnight at $4^{\circ} \mathrm{C}$. Slides were rinsed, as described, and exposed to the 
A

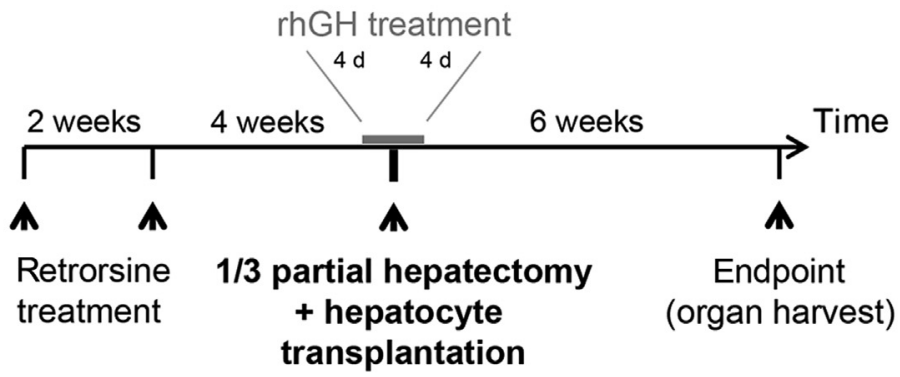

B

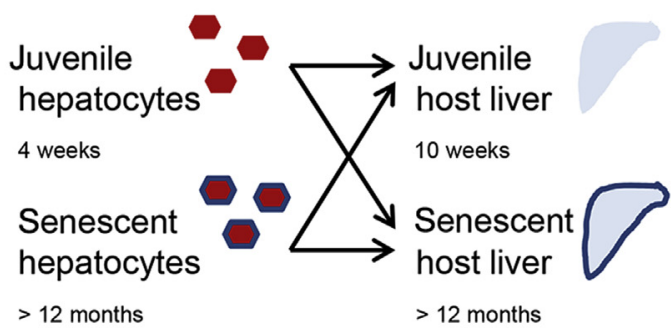

Figure 1 Experimental setup to study age-dependent liver repopulation by hepatocyte transplants. A: To provide donor hepatocytes with a growth advantage over host liver hepatocytes, host animals were pretreated at 6 and 4 weeks before cell transplantation with the natural pyrrolizidine alkaloid retrorsine, which inhibits hepatocyte proliferation. After partial hepatectomy, which triggers liver regeneration, cells were transplanted into the host liver via portal infusion and livers excised 6 weeks later for further analyses. Where indicated, rats were treated with rhGH (165 $\mu \mathrm{g}$ per animal) every 12 hours from 4 days before until 4 days after cell transplantation. B: Hepatocytes were isolated from wild-type rat livers, either juvenile ( 4 weeks) or senescent (over 12 months), and transplanted into livers of either juvenile (10 weeks at time of hepatocyte transplantation) or senescent (>12 months) recipient rats lacking expression of dipeptidyl-peptidase IV. This allows for the identification of DPPIV-expressing donor cells in the negative recipient liver background.

Alexa Fluor 555 anti-mouse secondary antibody (1:400). Slides were finally covered with DAPI Vectashield Mounting Medium containing DAPI $(1 \mu \mathrm{L} / \mathrm{mL})$ (Vector Laboratories) to visualize cell nuclei. Liver tissue from DPPIV-negative Fischer F344 rats served as a negative control.

Multiple immunofluorescence images were taken using appropriated filters mounted on an Eclipse, E600 fluorescence microscope (Nikon, Düsseldorf, Germany) and digitally merged using Adobe Photoshop CS6 (Adobe Systems, San José, CA).

\section{Immunohistochemistry for CYP Subtypes $3 \mathrm{~A} 4$ and 2E1}

To visualize protein expression of the retrorsine metabolizing enzyme cytochrome P450 (CYP) 3A4 and another perivenous marker CYP2E1, ${ }^{22-25}$ paraffin sections (1.5 $\mu \mathrm{m}$ thick) from livers of retrorsine-treated or untreated juvenile or senescent rats were analyzed by immunohistochemistry. Briefly, sections were deparaffinized stepwise and demasked for 35 minutes in freshly prepared citrate buffer (solution A, $10.5 \mathrm{~g}$ citric acid in $500 \mathrm{~mL}$ distilled water; solution $\mathrm{B}, 14.71 \mathrm{~g}$ sodium citrate in $500 \mathrm{~mL}$ distilled water; $9 \mathrm{~mL}$ solution $\mathrm{A}$ and $41 \mathrm{~mL}$ solution $\mathrm{B}$ were mixed with $450 \mathrm{~mL}$ distilled water and $\mathrm{pH}$ was adjusted to 6.0) using a pressure cooker. After cooling down in ice-cold water, endogenous peroxidases were blocked for $20 \mathrm{mi}-$ nutes at $4{ }^{\circ} \mathrm{C}$ in the dark using $3 \% \mathrm{H}_{2} \mathrm{O}_{2}$ in methanol. The slides were washed three times for 5 minutes with trisbuffered saline (TBS; $50 \mathrm{mmol} / \mathrm{L}$ Tris and $150 \mathrm{mmol} / \mathrm{L}$ $\mathrm{NaCl}, \mathrm{pH}$ 7.2) and dried for 3 minutes, followed by a 60 minute block with $5 \%$ bovine serum albumin (BSA) in $0.5 \%$ Tween 20 TBS at room temperature. Then, a 20minute avidin and biotin block each were performed at room temperature using the Avidin/Biotin Blocking Kit from Vector Laboratories. Slides were rinsed shortly in TBS, and primary antibody (CYP3A4, 1:100, or CYP2E1, 1:100) (Table 1) in 1\% BSA in TBS was applied. The slides were incubated overnight at $4{ }^{\circ} \mathrm{C}$. After washing the slides three times for 7 minutes with TBS, the biotinylated secondary antibody (Table 1) in $0.5 \%$ BSA in TBS was applied and slides were incubated for 70 minutes at room temperature. After washing three times for 7 minutes with TBS, slides were incubated with VECTASTAIN Elite ABC HRP Kit from Vector Laboratories, according to the manual, for 30 minutes. Slides were washed two times for 5 minutes, followed by the staining procedures: to visualize CYP3A4, slides were incubated with Pierce Stable Peroxide Substrate Buffer from Thermo Fisher Scientific (Waltham, MA) for 1 to 2 minutes at room temperature, and to visualize CYP2E1, slides were incubated with VECTOR NovaRED Peroxidase (HRP) Substrate Kit from Vector Laboratories for $4 \mathrm{mi}-$ nutes. Thereafter, slides were rinsed with TBS and counterstained with nuclear fast red for up to 5 minutes. Slices were stepwise dehydrated and coverslips mounted with Entellan (Merck, Darmstadt, Germany). The slides were analyzed by light microscopy using the AXIO Imager.A1 from Zeiss (Oberkochen, Germany), and images were captured by using ZEN pro software version 2012 from Zeiss.

\section{Immunohistochemistry for Ki-67 and Colocalization with DPPIV}

To calculate the percentages of proliferating hepatocytes, the expression of Ki-67, a marker of cell cycle progression through the $G_{1}, S, G_{2}$, and $M$ phases, was visualized in paraffin sections ( $1.5 \mu \mathrm{m}$ thick) from juvenile or senescent rat livers by immunohistochemistry. To colocalize the proliferation marker with the clusters of engrafted hepatocytes, tissue sections were costained for DPPIV expression. Briefly, sections were stepwise deparaffinized and 30 minutes demasked, as described above. After cooling down in ice-cold water, the peroxidases were blocked for 20 minutes at $4{ }^{\circ} \mathrm{C}$ in the dark using $3 \% \mathrm{H}_{2} \mathrm{O}_{2}$ in methanol. 
The slides were washed three times for 5 minutes with TBS and dried for 3 minutes, followed by a 60-minute block with $5 \%$ BSA in $0.5 \%$ Tween 20 TBS at room temperature. Then, endogenous avidin and biotin binding sites were blocked for 20 minutes each at room temperature using the Avidin/Biotin Blocking Kit from Vector Laboratories. Slides were rinsed shortly in TBS, and the first primary antibody (DPPIV, 1:100) (Table 1) in 1\% BSA in TBS was applied overnight at $4{ }^{\circ} \mathrm{C}$. After washing three times for 5 minutes with TBS, the first biotinylated secondary antibody (Table 1) in $0.5 \%$ BSA in TBS was applied and incubated for 70 minutes at room temperature. After washing two times for 5 minutes with TBS, slides were incubated with the VECTASTAIN Elite ABC HRP Kit from Vector Laboratories, according to the manual, for 30 minutes. Slides were washed three times for 5 minutes with TBS and developed with VECTOR NovaRED Peroxidase (HRP) Substrate Kit, as decribed above. Slides were rinsed in aqua dest. and to avoid cross-reactions with the first antibody, the LinBlock (Linaris Biologische Produkte $\mathrm{GmbH}$, Dossenheim, Germany) was performed additionally for 10 minutes. Then, liver sections were incubated overnight at $4^{\circ} \mathrm{C}$ with the second primary Ki-67 antibody (Table 1) in 1\% BSA in TBS. Slides were washed three times for 5 minutes in TBS and incubated with the second biotinylated secondary antibody (Table 1) in $0.5 \%$ BSA in TBS for 70 minutes at room temperature. Slides were washed two times for 5 minutes with TBS and incubated for 30 minutes with VECTASTAIN Elite ABC HRP Kit from Vector Laboratories. After washing the slides three times for 5 minutes with TBS, the staining was developed with Pierce Stable Peroxide Substrate Buffer from Thermo Fisher Scientific for 30 seconds. After stepwise dehydration, coverslips were mounted onto the slides with Entellan. The slides were analyzed by light microscopy, and images were captured as described above.

Percentages of proliferating cells were determined in liver tissues from three individual rats $(N=3)$. Fifteen microscopic fields each $(n=15)$ were randomly chosen, and nuclei stained for Ki-67 were counted. The percentage of proliferating cells was calculated as amount of proliferating (Ki-67 positive) relative to the total number of hepatocytes. Percentages were determined in control livers from untreated juvenile and senescent rats; in liver resectates of retrorsine-treated juvenile and senescent rats taken at the time point before hepatocyte transplantation; in livers of retrorsine-treated juvenile and senescent animals 6 weeks after hepatocyte transplantation; in livers of retrorsinetreated and recombinant human $\mathrm{GH}(\mathrm{rhGH})$-treated senescent animals 6 weeks after hepatocyte transplantation and in retrorsine-treated senescent animals 6 weeks after transplantation of rhGH-treated hepatocytes.

\section{DNA Microarray Analysis}

For comparative gene expression analysis, processed data from Gene Expression Omnibus accession number
GSE51657 (https://www.ncbi.nlm.nih.gov/geo) (Agilent028279 SurePrint G3 Rat GE $8 \times 60$ K Microarrays) were used $^{26}$ [namely, five samples from 3-month-old rat livers (GSM1250194 to GSM1250198) and six samples from 14-month-old rat livers (GSM1250204 to GSM1250209)]. Differentially expressed genes were identified by using MAFilter software version 1.0.2 (Danial S. Steingrube, Hanover, Germany; http://steingrube-home.de/software MAFilter.html), as described. ${ }^{27}$ Genes with a Welch's $t$-test $P$ value $<0.01$ and a Wilks' $\lambda$ score $>2$ were considered to be differentially expressed between young and aged rats. In addition, DNA microarray analysis from juvenile and senescent human livers was performed by using Affymetrix HG-U133A microarrays GEO accession number GSE87889, as described. ${ }^{28}$ HG-U133A data sets were processed by using Microarray Suite 5.0 algorithm and scaled to the same target intensity of 500. Analysis was performed by using Gene Array Enrichment Analysis (Gene Set Enrichment Analysis) software version 2.0 (The Broad Intitute of MIT and Harvard, Cambridge, MA $)^{29,30}$ clustering for gene ontology biological processes. $^{31-34}$ Data visualization and cluster analysis was performed by using the Genesis software package version 1.7.7.0 (Graz University of Technology, Graz, Austria). ${ }^{35}$

\section{Enrichment Analysis}

Microarray data (GEO accession number GSE87889) were annotated to enable functional interpretation to allow for a better mechanistic understanding of the host environment via enrichment analysis (GEO accession number GSE87889). Gene ontology AmiGO 2 (version 2.4.24) (1-34 $^{31-1}$ analysis was performed on the selected list of genes using a cutoff $<-3$ and $>3 \log 2$ fold-change between genes expressed in juvenile and senescent livers.

\section{Western Blot Analysis}

Soluble protein $(30 \mu \mathrm{g})$ was subjected to $10 \%$ SDS$\mathrm{PAGE}^{36}$ and transferred onto polyvinylidene difluoride membranes. Membranes were blocked with 5\% nonfat milk in $20 \mathrm{mmol} / \mathrm{L}$ Tris and $150 \mathrm{mmol} / \mathrm{L} \mathrm{NaCl}, \mathrm{pH} \mathrm{7.5}$, and probed with primary antibodies (Table 1) for 2 hours. A horseradish peroxidase-conjugated secondary antibody was used to detect proteins of interest using the enhanced chemiluminescence detection system (GE Healthcare, Freiburg, Germany) and exposure to a photographic film. Densitometric analysis was performed using ImageJ version 1.48 (NIH, Bethesda, MD; http://imagej.nih.gov/ij).

\section{Determination of Functional Properties in Vitro}

The proliferation rate of cultured rat hepatocytes was measured by counting cell numbers using a FuchsRosenthal counting chamber after detachment of the cells from the culture dishes by $0.05 \%$ trypsin digestion. 
Urea synthesis by cultured hepatocytes was determined within the culture periods, as indicated using a diacetyl monoxime method (blood urea nitrogen). Culture medium was changed every 24 hours, and urea formed by the cells was determined in the medium along with standard dilutions in hepatocyte growth medium, according to the manufacturer's instructions. The colored product was measured at $540 \mathrm{~nm}$.

The 7-ethoxyresorufin-O-deethylase and 7-pentoxyresorufinO-depentylase enzyme activities were measured by incubating intact rat hepatocytes with $8 \mu \mathrm{mol} / \mathrm{L}$ 7-ethoxyresorufin or $15 \mu \mathrm{mol} / \mathrm{L}$ 7-pentoxyresorufin, respectively, for 2 hours. Dicumarol $(10 \mu \mathrm{mol} / \mathrm{L})$ was added to prevent further metabolism of the product resorufin by the cytosolic enzyme diaphorase. Thereafter, 15 Fishman units of $\beta$-glucuronidase and 120 Roy units of arylsulfatase were added and incubation continued for 2 hours. The products formed were quantified fluorimetrically.

\section{Flow Cytometry}

Hepatocytes transplanted via the portal tract distribute heterogeneously within the liver. ${ }^{37}$ For this reason, the number of transplanted cells could be quantified after isolation of hepatocytes from the whole recipient livers, as described above, and cell suspensions stained with the anti-DPPIV antibody in PBS supplemented with $1 \%$ fetal bovine serum. A total of 40,000 hepatocytes from each liver were analyzed by flow cytometry using the FACS Calibur and CellQuest software version 2.0 (BD, Heidelberg, Germany). Results were evaluated using the WinMDI software version 2.9 (Joe Trotter, The Scripps Institute, Flow Cytometry Core Facility, La Jolla, CA).

\section{Immunocytochemistry for PCNA}

Primary hepatocytes isolated from either juvenile or senescent DPPIV-positive Fischer 344 rats were plated on collagen-coated coverslips and cultured as described above. On days 3 and 8 of culture, coverslips were removed and fixed in ice-cold acetone/methanol, 1:1, for 20 minutes at $-20^{\circ} \mathrm{C}$. The coverslips were washed three times with PBS, incubated for 1 hour in $0.5 \%$ Tween 20 in PBS, blocked for 1 hour in 5\% BSA in PBS, and additionally blocked for 10 minutes in Block Solution from Dako (Hamburg, Germany) at room temperature. Afterward, the primary antibody against proliferating cell nuclear antigen (PCNA) was applied and coverslips were gently rocked overnight at $4^{\circ} \mathrm{C}$. Then, they were washed as described and incubated for 1 hour with the Alexa Fluor 555 anti-mouse secondary antibody, 1:400, at room temperature. After washing, the coverslips were mounted onto slides with DAPI Vectashield Mounting Medium containing DAPI $(1 \mu \mathrm{L} / \mathrm{mL})$. PCNApositive nuclei were counted in three independent replicates and percentages were calculated.

\section{Growth Hormone Treatment}

DPPIV-negative, senescent Fischer F344 rats destined for cell transplantation were injected every 12 hours from 4 days before to 4 days after hepatocyte transplantation, receiving a s.c. dose of $165 \mu \mathrm{g}$ rhGH per rat (Nordiflex; Novo Nordisk, Mainz, Germany). Control animals received PBS only.

On the basis of the half-life time of rhGH in vivo of approximately 20 minutes, ${ }^{38}$ and the expected slow hormone clearance rate in cell culture, ${ }^{39}$ freshly isolated primary hepatocytes from senescent rats were treated in culture for 4 hours with a single dose of rhGH $(2 \mu \mathrm{g} / \mathrm{mL})$ added to the plating medium, minimal essential medium.

\section{Determination of Circulating GH and IGF-I Concentrations}

Blood samples taken from the tail vein were allowed to clot for 1 hour and tubes were centrifuged for 10 minutes at $560 \times g$ and $4^{\circ} \mathrm{C}$. Concentrations of rat $\mathrm{GH}$ in the serum were determined in juvenile and senescent animals before transplantation as well as in senescent animals with rhGH treatment for 4 days until cell transplantation and in treated animals at the final hepatectomy 6 weeks after cell transplantation. Total rat GH was analyzed in serum samples using a commercially available kit (Mediagnost, Tübingen, Germany), according to the manufacturer's instructions. Serum concentrations of exogenously administered rhGH were analyzed in senescent rats by using a time-resolved fluorescence assay that does not cross-react with endogenous rodent $\mathrm{GH}$.

Total insulin-like growth factor (IGF-I) was analyzed in serum samples using a commercially available kit (IDS, Boldon, UK), according to the manufacturer's instructions. A detailed description of the method has been published elsewhere. $^{40,41}$

\section{Statistical Analysis and Software}

Statistical analyses were conducted by the unpaired $t$-test using SigmaPlot version 9.0 (Systat Software $\mathrm{GmbH}$, Erkrath, Germany). All experiments were repeated at least three times.

\section{Results}

Host Age-Dependent Liver Repopulation by Transplanted Hepatocytes

The efficiency of repopulation was assessed qualitatively by histochemical detection of DPPIV activity and quantitatively by flow cytometry. Transplantation of either juvenile or senescent hepatocytes into juvenile host livers yielded average repopulations of $21.5 \%$ and $19.5 \%$, respectively (Figure 2, A and C). Yet, repopulation was only $0.9 \%$ and 
$1.4 \%$, respectively, transplanting juvenile or senescent hepatocytes into senescent livers (Figure 2, B and D). Thus, irrespective of the donor age, transplanted hepatocytes formed big clusters in juvenile host livers and only small clusters in senescent host livers, indicating that repopulation was governed by host liver-derived signals.

Retrorsine is mainly metabolized by CYP3A4 and metabolites generated form DNA adducts inducing replicative senescence. ${ }^{16,23,42}$ Hence, differences in expression pattern or amount might cause differences in repopulation rates in juvenile versus senescent rats. We examined the expression of CYP3A4 and another perivenous marker, CYP2E1, in livers of juvenile (4 weeks) and senescent (14 months) host animals before and 6 weeks after retrorsine treatment, the latter taken from the resectates of partial hepatectomy at the point in time of hepatocyte transplantation, and 6 weeks after hepatocyte transplantation. No differences in zonation or extent in protein expression of CYP2E1 or CYP3A4 were observed before and 6 weeks after retrorsine treatment (Figure 3, A-H) between juvenile and senescent rats. Although expression of CYP2E1 was consistently restricted to perivenous hepatocytes both in juvenile and senescent rats under all experimental conditions (Figure 3, A, B, E, F, I, J, and K), zonated expression of CYP3A4 seemed to disappear in both juvenile and senescent animals treated with retrorsine 6 weeks after hepatocyte transplantation (Figure 3, L and M). Hence, even if addressed indirectly, we conclude that differences in repopulation by transplanted hepatocytes between juvenile and senescent host livers were bona fide not because of differences in metabolism of retrorsine. To substantiate this argument, hepatocytes were isolated from juvenile or senescent rat livers and their metabolic competence was also tested in vitro (see the next section).

\section{Senescent and Juvenile Hepatocytes Displayed Similar Functional Features in Vivo and in Vitro}

Functional deficiencies might impede the repopulation by transplanted hepatocytes in the aged liver. Therefore, the metabolic capacity and cell/cell communication were compared in juvenile and senescent hepatocytes after transplantation into juvenile animals. Glycogen storage in transplanted hepatocytes was monitored in combination with the enzymatic detection of DPPIV. Donor cell clusters of comparable size were visible using juvenile or senescent transplants. The intensity of the periodic acid-Schiff stain did not differ between the juvenile or senescent transplants nor from the surrounding host parenchyma (Figure 4, A and C). No significant repopulation was achieved on transplantation into senescent host livers, albeit these stored glycogen (Figure 4, B and D).

To detect a potential difference of parenchymal entry between juvenile and senescent hepatocytes, which enter the host parenchyma predominantly in periportal areas of the liver lobule, ${ }^{43}$ cells were transplanted into juvenile host livers and their regional integration was visualized by the costaining of DPPIV in donor cells and glutamine synthase in perivenous host hepatocytes. Both donor cell populations formed large clusters expanding from the periportal into the perivenous parenchyma of the host liver (Figure 4, E and G). Costaining of DPPIV with the gap junction protein

\section{Host}

Juvenile
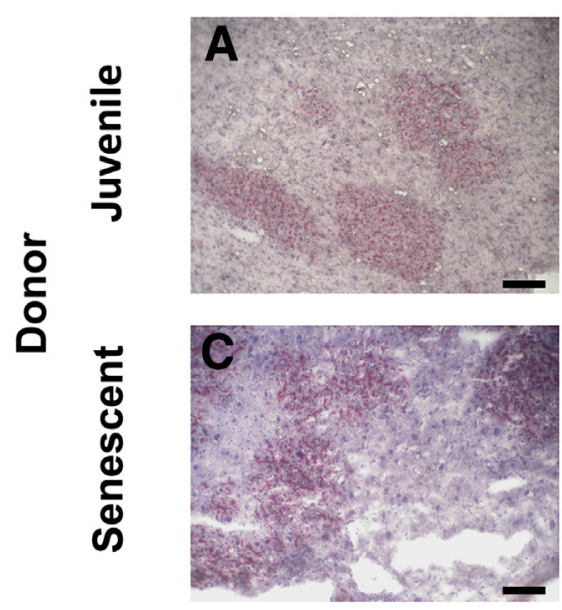
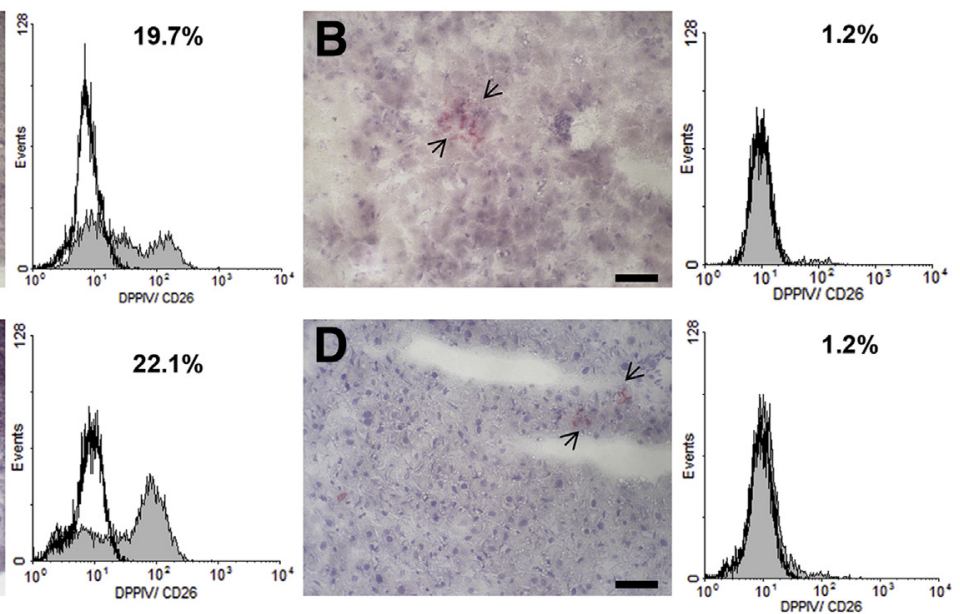

Figure 2 Repopulation of DPPIV-negative host livers by transplanted wild-type DPPIV-positive hepatocytes. DPPIV enzyme activity was visualized histochemically, and the percentage of donor hepatocytes in the host liver parenchyma was quantified by flow cytometry. Juvenile (A and B) or senescent (C and D) hepatocyte transplantation into juvenile and senescent host livers, respectively. Values given are representative percentages of the donor cells in host livers. Arrows in B and D point to small donor cell clusters. Gray areas in the histograms illustrate the fraction of donor cells in the total hepatocyte preparation; white areas, the isotype control. $n=3$ (A-D). Scale bars $=100 \mu \mathrm{m}$ (A-D). 

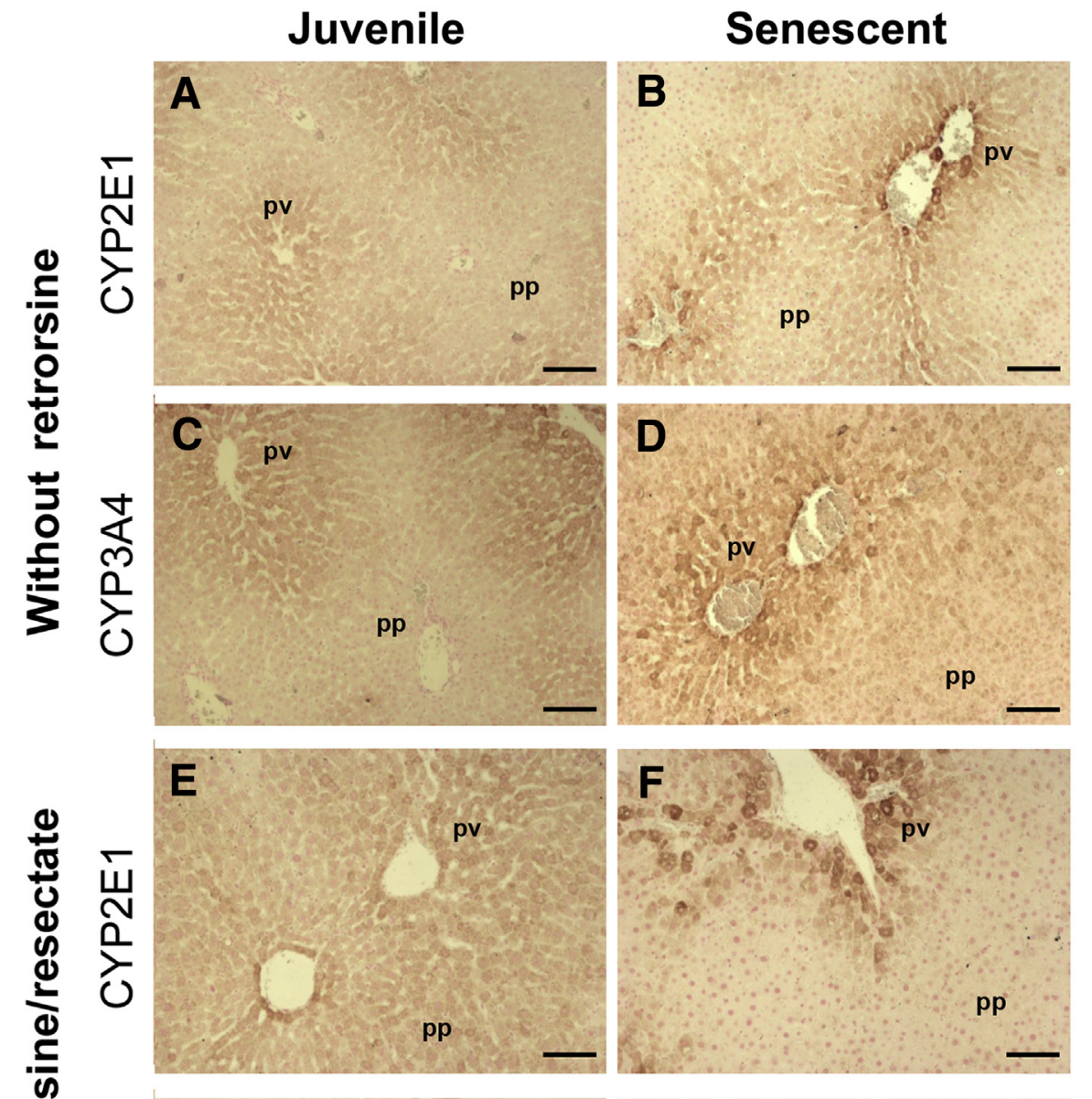

Figure 3 Zonal expression of CYP2E1 and CYP3A4 in juvenile and senescent host livers with and without retrorsine treatment. Zonal protein expression of CYP2E1 (A, B, E, F, and I-K) and CYP3A4 (C, D, G, H, and $\mathbf{L}-\mathbf{N}$ ) were visualized by immunohistochemistry on liver sections of juvenile (4 weeks) and senescent (14 months) rats without retrorsine treatment $(\mathbf{A}-\mathbf{D})$, liver sections from resectates of juvenile (10 weeks) and senescent ( $>12$ months) rats treated for 6 weeks with retrorsine, taken at the time point of hepatocyte transplantation $(\mathbf{E}-\mathbf{H})$, liver sections of host animals at the end of experiment, 6 weeks after hepatocyte transplantation (I-N), and liver sections of rhGH-treated host rats ( $\mathbf{K}$ and $\mathbf{N}$ ). Although perivenous ( $\mathrm{pv}$ ) expression and expression levels of CYP2E1 were similar under all conditions tested, zonal expression of CYP3A4 disappeared both in juvenile and in senescent livers of retrorsine-treated animals 6 weeks after hepatocyte transplantation ( $L$ and $\mathbf{M})$. Eventually, expression could also be detected in periportal (pp) hepatocytes. Scale bars $=100 \mu \mathrm{m}(\mathbf{A}-\mathbf{N})$.

\section{Senescent after GH treatment}

pp
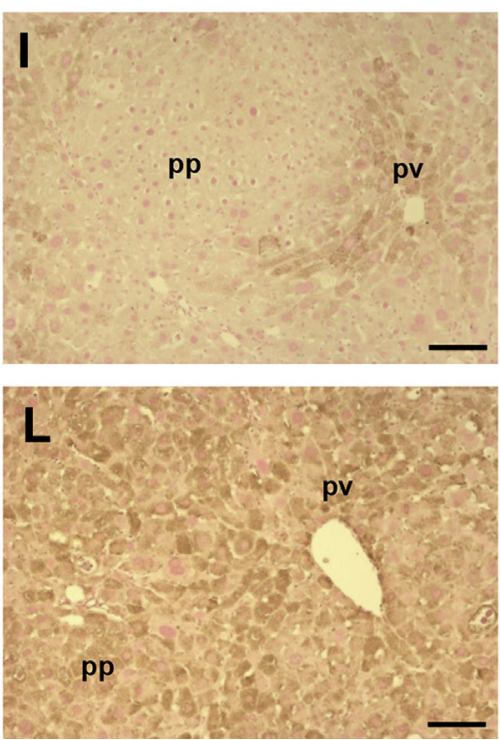
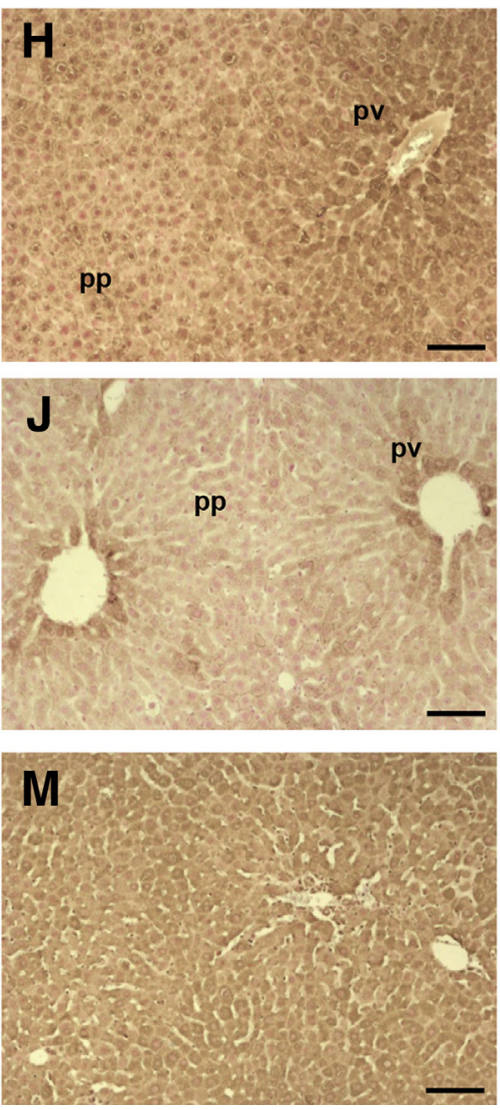

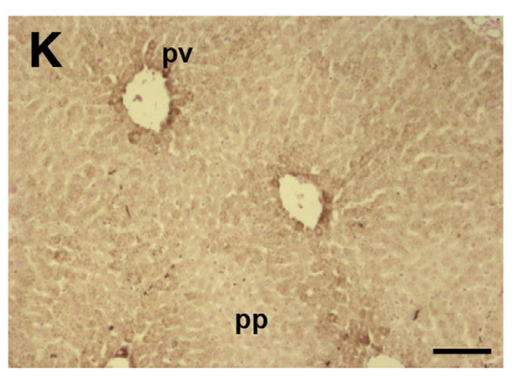

N

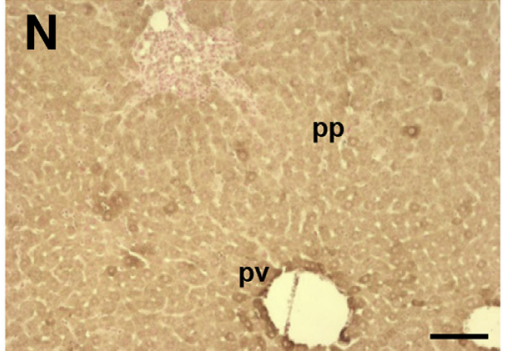



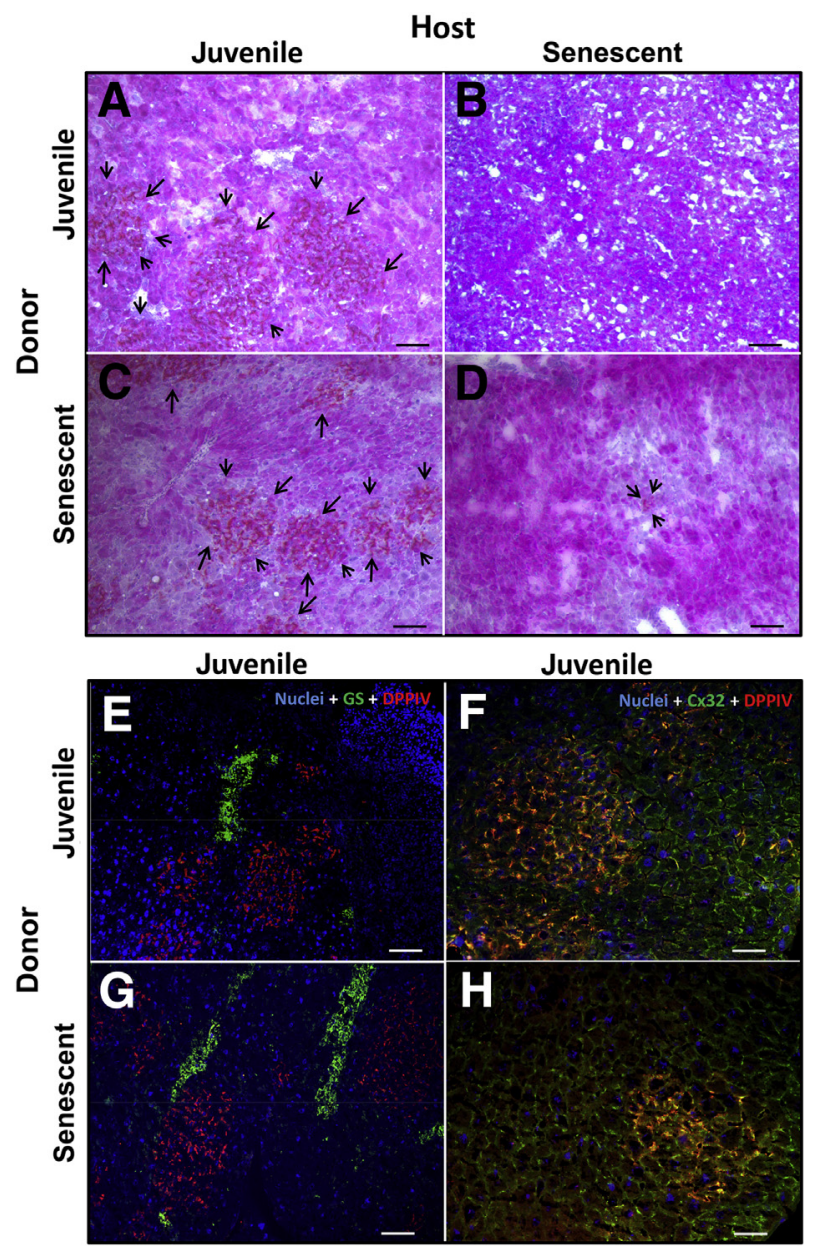

Figure 4 Functional capabilities of transplanted hepatocytes in vivo. A-D: Glycogen storage (purple) and DPPIV enzyme activity (red) indicate functional cell transplants in the host parenchyma after juvenile (A and $\mathbf{B}$ ) or senescent ( $\mathbf{C}$ and $\mathbf{D}$ ) hepatocyte transplantation into juvenile and senescent host livers, respectively. Arrows show clusters of donor cells. $\mathbf{E}-\mathbf{H}$ : Functional properties of donor juvenile (E and $\mathbf{F}$ ) or senescent $(\mathbf{G}$ and $\mathbf{H})$ hepatocytes were investigated in juvenile host livers. The proliferative capacity was estimated by the size of donor cell clusters (red; $\mathbf{E}-\mathbf{H})$, and functional integration by the expression of connexin 32 ( $\mathrm{C} \times 32$; green; $\mathbf{F}$ and $\mathbf{H})$. Glutamine synthase (GS; green; $\mathbf{E}$ and $\mathbf{G})$ indicates perivenous areas of the parenchyma; blue color nuclei. Scale bars = $100 \mu \mathrm{m}(\mathbf{A}-\mathbf{H})$.

Cx32 indicated that both donor cell populations built gap junctions between neighboring donor cells and host hepatocytes (Figure 4, F and $\mathrm{H}$ ). Thus, in vivo, no differences in the proliferative and functional properties between juvenile and senescent donor hepatocytes were detected, suggesting that senescent host liver-derived signals governed repopulation efficiency.

Functional features of donor hepatocytes were further characterized in cultured hepatocytes. Neither xenobiotics metabolism nor urea synthesis was different between juvenile and senescent hepatocytes (Supplemental Figure S1). As previously shown in vivo by a similar tissue expansion of juvenile and senescent donor cell-derived cell clusters in juvenile recipient livers (Figure 4, E-H), the proliferative properties were similar also in vitro, as detected by counting cell numbers after stimulation with hepatocyte and epidermal growth factor. The increase in cell numbers of juvenile and senescent hepatocytes at day 8 of culture was 2.83- \pm 0.6 -fold (SEM) and 1.56- \pm 0.08 -fold (SEM), respectively, over starting levels at day 1 of culture. Even if lower in cultures of senescent hepatocytes, this increase was not significantly different from juvenile hepatocytes. This was confirmed by quantitative analyses of the cell cycle proteins cyclins D1 and D3, indicating progression from $\mathrm{G}_{1}$ into the $\mathrm{S}$ phase and PCNA, indicative of proliferating cells in the $\mathrm{S}$ phase of the cell cycle. As shown in two representative preparations, cyclin D1 and D3 expression increased with time of culture, reaching peak levels between days 6 and 8 (Figure 5A). Quantitative analyses of the four experiments performed revealed no significant differences between juvenile and senescent hepatocytes (data not shown). PCNA was stained to determine the proliferation rate in juvenile and senescent hepatocytes after 3 and 8 days of culture. Although at day $8,40 \%$ to $50 \%$ of juvenile and senescent hepatocytes were proliferating, the proliferation rate at day 3 was approximately twice as high in senescent $(25 \%)$ as in juvenile (10\%) hepatocytes (Figure 5B).

Thus, juvenile and senescent hepatocytes displayed virtually no differences in metabolic functions and proliferative capacities, again suggesting that repopulation of host livers depended on signals emanating from the host environment.

\section{Growth Hormone Augmented Repopulation of Senescent Host Livers}

Low circulating concentrations of $\mathrm{GH}$, which is a major mitogen for solid organs, might contribute to the impairment of repopulation in senescent livers. ${ }^{11}$ In rodents, GH affected hepatic growth, rendering liver weights a sensitive indicator of the endogenous GH status. ${ }^{40}$ Serum concentrations of growth hormone were significantly lower in senescent than in juvenile rats (Figure 6A). Treatment of senescent hosts with rhGH significantly increased the circulating rhGH levels as compared to controls receiving PBS (Figure 6B) without affecting the endogenous rat GH serum levels $(56.3 \pm 13.6 \mathrm{ng} / \mathrm{mL})$. These remained in the range of levels in senescent rats (Figure 6A). As a biological response of rhGH, IGF-I serum levels were measured. They were lower in untreated senescent than in juvenile rats, but were increased to juvenile levels by the treatment with rhGH. Thus, rhGH was active in the rat, albeit only transiently (Supplemental Figure S2).

Senescent host animals were treated with rhGH to augment the repopulation of senescent rat livers. Irrespective of the age of the donor cells, the repopulation rate in senescent host livers was significantly higher (Figure 7, A and B) as compared to untreated controls (Figure 2, B and D). Large clusters of cell transplants were visible, representing functional donor cells as visualized by the 


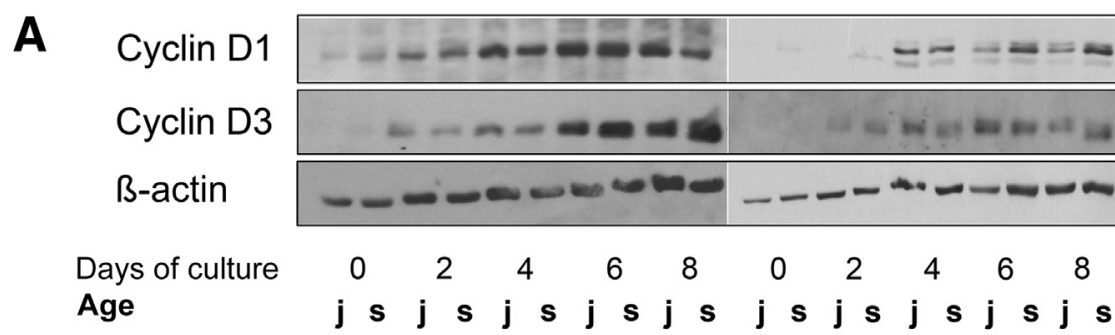

B

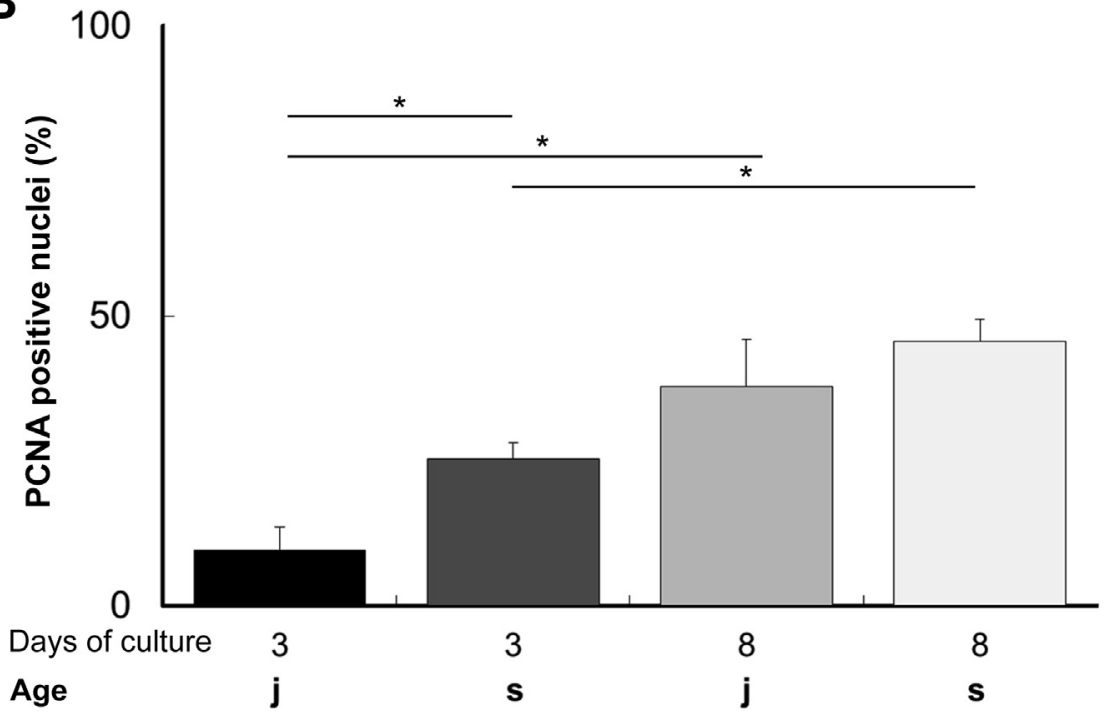

Figure 5 Proliferative capacities of juvenile and senescent hepatocytes in vitro. A: Western blots of cytosolic extracts from juvenile (j) and senescent (s) hepatocytes at different times of culture were probed with anti-cyclin D1 or D3 antibodies (two of four experiments shown). Quantitative normalization to $\beta$-actin yielded no differences between juvenile and senescent hepatocytes (data not shown). B: Juvenile and senescent hepatocytes were cultured for 3 and 8 days, and the proliferation rate was calculated as percentage of proliferating cell nuclear antigen (PCNA)-positive nuclei relative to total nuclei. Data are expressed as means \pm SEM (B). $n=3$ experiments (B). ${ }^{*} P<0.05$. costain of DPPIV enzyme activity and glycogen (periodic acid-Schiff) (Figure 7, C and D). Thus, the temporary short-term treatment of the senescent host with rhGH significantly improved the repopulation of the host liver, albeit not reaching levels as in juvenile hosts (Figure 2, A and C). This boost relied solely on host-derived effects because the treatment of isolated hepatocytes with rhGH before transplantation into senescent hosts did not improve repopulation (Supplemental Figure S3).

To gain a basic understanding of the mechanism by which GH might improve repopulation of senescent livers by transplanted hepatocytes, the proliferation of hepatocytes in juvenile and senescent livers was compared by analyzing Ki-67-positive cell nuclei in both the host parenchyma before hepatocyte transplantation and the host parenchyma and the donor cell clusters 6 weeks after transplantation.

Quantification of Ki-67-expressing nuclei revealed no significant differences in the response to retrorsine treatment in juvenile and senescent livers at the time point of hepatocyte transplantation, ${ }^{46}$ which was $9.35 \%$ in juvenile and $8.74 \%$ in senescent host animals. Percentages decreased to $1.4 \%$ in juvenile and to $2.4 \%$ in senescent host livers 6 weeks after hepatocyte transplantation, again corroborating a comparable effectiveness of retrorsine treatment in young and old animals. Percentages of proliferating hepatocytes in the clusters of transplanted cells were $4.2 \%$ in juvenile and $0 \%$ in senescent hosts. Proliferation in cell clusters of senescent host animals was not affected by treatment with growth hormone (ie, it remained 0\%). Because repopulation in these animals achieved approximately 4\% (Figure 7), GH treatment was likely effective only for a short duration after transplantation. We might not rule out a direct effect of $\mathrm{GH}$ on the transplanted cells. However, GH treatment of isolated hepatocytes before transplantation did neither affect the proliferation of the cells in culture nor improve repopulation after transplantation, indicating that enhancement of repopulation by $\mathrm{GH}$ needed cross talk between cell transplants and the preconditioned host liver.

GH treatment also did not alter distribution and expression levels of CYPs 3A4 and 2E1 as compared to untreated animals (Figure 3, $\mathrm{K}$ and $\mathrm{N}$, versus Figure 3, $\mathrm{J}$ and $\mathrm{M}$ ), demonstrating that improvement of repopulation was not because of differences in retrorsine metabolism and effectiveness.

\section{Growth Hormone Might Alleviate Cell Cycle Progression} of Hepatocytes in a Senescent Host Liver

It has been shown that GH might resolve cell cycle pausing in senescent hepatocytes. Cell cycle progression is hampered by the sequestration of the transcription factor E2F in a protein complex with retinoblastoma and 

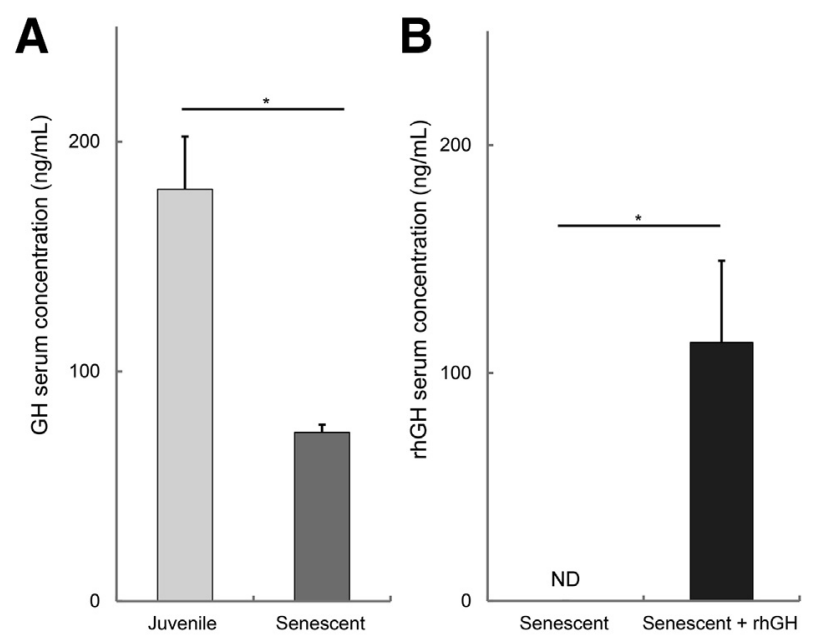

Figure 6 Growth hormone levels in the serum of juvenile and senescent host rats at the point in time of hepatocyte transplantation. A: Normal GH levels in juvenile (light gray bar) and in senescent (dark gray bar) host rats. B: Serum levels of rhGH in senescent rats 4 days after administration of rhGH or phosphate-buffered saline as the solvent control. Significant differences were detected between groups, as indicated by the horizontal lines. Data are expressed as means \pm SEM from three different animals, each run in duplicate $(\mathbf{A}$ and $\mathbf{B})$. ${ }^{\star} P<0.05$. ND, not detectable.

chromatin remodeling factor Brahma after cyclin D3dependent phosphorylation of CCAAT/enhancer-binding protein $\alpha(\mathrm{C} / \mathrm{EBP} \alpha)$ entering the complex and finally pausing transcription of genes associated with proliferation, like c-myc. Stimulation of protein phosphatase $2 \mathrm{~A}$ by noncanonical GH signaling leads to dephosphorylation of
$\mathrm{C} / \mathrm{EBP} \alpha$, dissociation of the complex, and finally release of the transcriptional block. ${ }^{13}$ Therefore, we determined the relative abundance of components of the complex by Western blotting to delineate a relationship of senescent host liver repopulation with a potential transcriptional blockade of proliferation. Expression levels of C/EBP $\alpha$, retinoblastoma, cyclins D1 and D3, protein phosphatase 2A, and PCNA, a downstream target of the complex, were investigated in resectates from juvenile and senescent as well as in senescent livers after rhGH treatment. C/EBP $\alpha$, retinoblastoma, and cyclin D3 were significantly higher in senescent than in juvenile livers. Treatment with rhGH reduced levels to values comparable to those in juvenile livers. Protein phosphatase 2A, PCNA, and cyclin D1 were significantly lower in senescent than in juvenile host livers, which could be increased again by rhGH treatment to levels observed in juvenile livers. This indicated a higher replicative potential in juvenile than in senescent livers (Figure 8). Yet, short-term GH treatment of senescent livers restored the replicative environment to levels comparable to juvenile livers.

\section{Gene Enrichment Analysis to Assess Host Liver Environments}

To obtain a broader view on additional factors or conditions that might constitute the hepatic microenvironment to drive and affect repopulation of the host liver by transplanted hepatocytes, gene enrichment analyses were performed using existing DNA microarray data sets from young (3 months) and senescent (14 months) rat livers, as
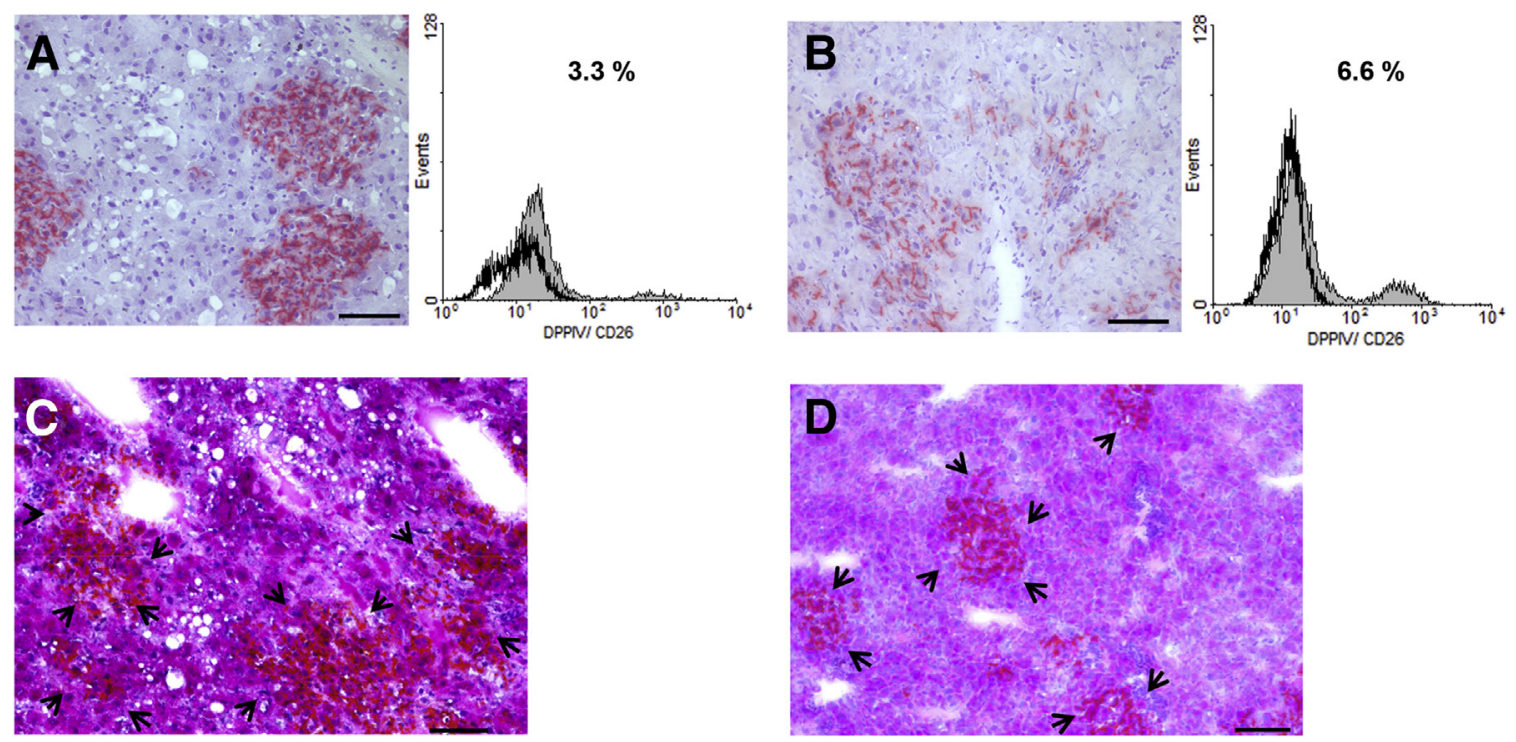

Figure 7 Repopulation of senescent host livers after conditioning with rhGH. Juvenile (A and C) or senescent (B and D) hepatocytes, respectively, were transplanted into senescent rats treated with rhGH. A and B: DPPIV enzyme activity was visualized, and the percentage amount of donor hepatocytes was quantified by flow cytometry. Gray areas in histograms illustrate the fraction of donor cells in the total hepatocyte preparation; white areas, the isotype control. Values given are representative percentages of the donor cells in host livers from three different experiments, each run in triplicate. $\mathrm{C}$ and D: Colocalization of DPPIV enzyme activity (red) with glycogen storage (purple). Arrows in $\mathbf{C}$ and $\mathbf{D}$ indicate donor cell clusters. Scale bars $=$ $100 \mu \mathrm{m}$ (A-D). 

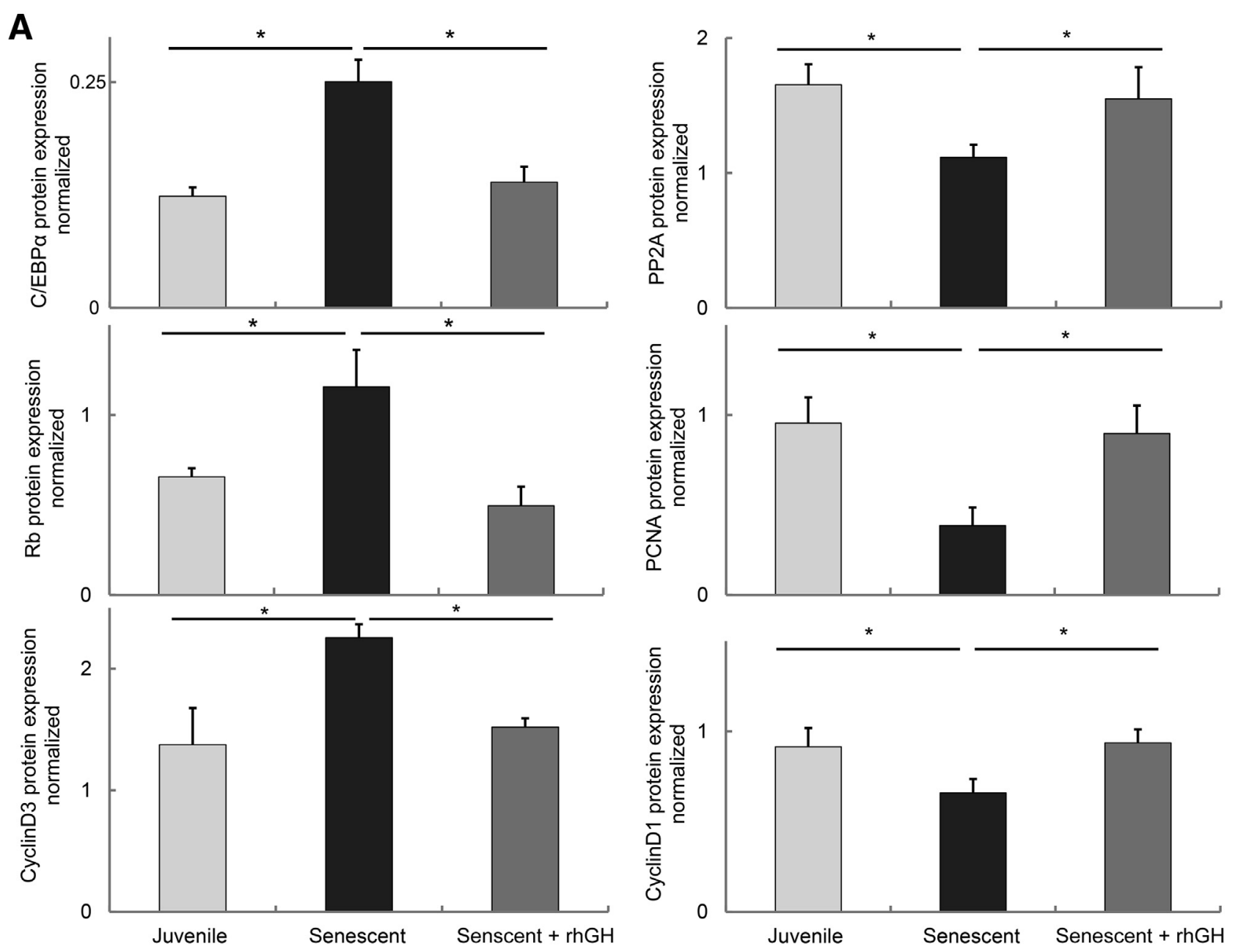

B

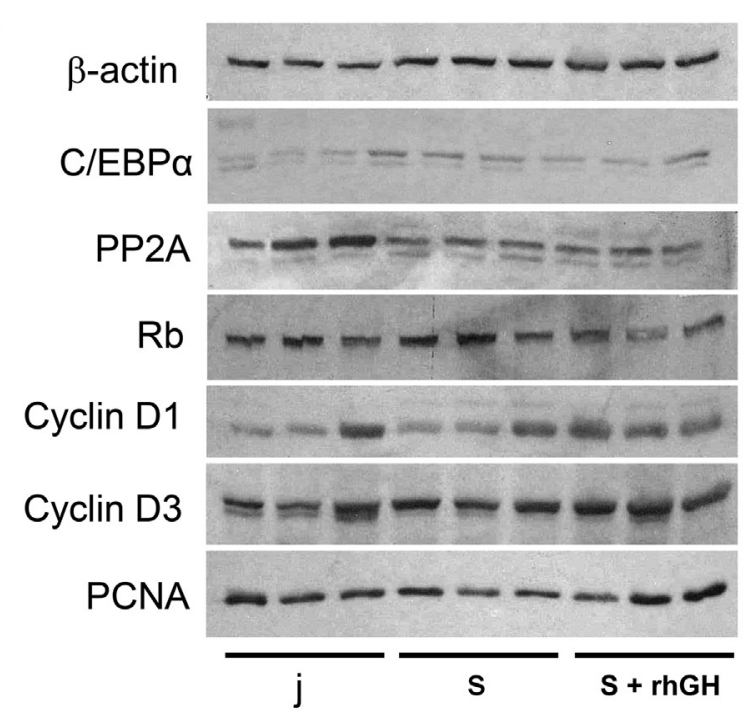

described under Materials and Methods. The results of the cluster analysis of genes differentially expressed revealed the significant up-regulation of cyclin D3 (Ccnd3) gene expression in senescent livers, as indicated in Figure 9, corroborating results on the protein level, as shown in

Figure 8 Reconstitution of the proliferative capacity in senescent rat livers by growth hormone. A: The expression of CCAAT/ enhancer-binding protein $\alpha(\mathrm{C} / \mathrm{EBP} \alpha ; 42 \mathrm{kDA})$, protein phosphatase 2A (PP2A), retinoblastoma (Rb), cyclin D1, cyclin D3, and proliferating cell nuclear antigen (PCNA) was determined in liver resectates of juvenile (j), senescent ( $(\mathrm{s})$, and senescent animals treated with rhGH. Levels were estimated by normalization for $\beta$ actin expression. B: Western blots illustrating three different protein preparations in each group, as shown in $\mathbf{A}$. Data are expressed as means \pm SEM of six different experiments in either group, each run in duplicate $(\mathbf{A}) .{ }^{*} P<0.05$.

Figure 8. Furthermore, another 264 probes were identified as significant differentially expressed genes (Supplemental Table S1), among those ICAM-1 (CD54) and Casp12. Because intercellular adhesion molecule-1 gene expression is induced by proinflammatory 


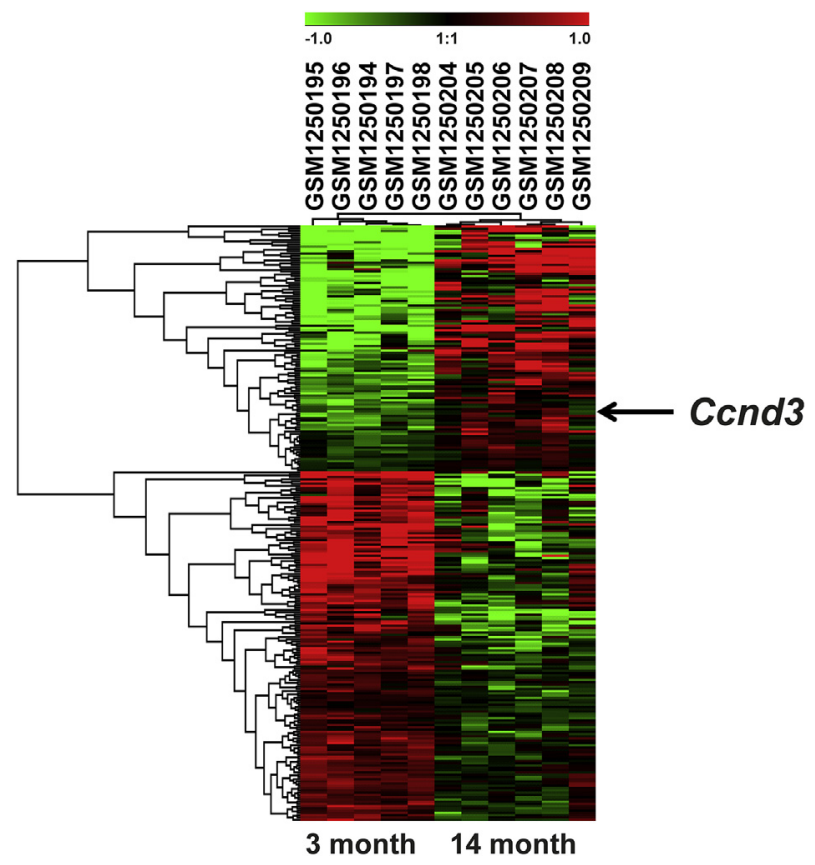

Figure 9 Cluster analysis of genes differentially expressed between young and senescent rat livers. Microarray data from liver samples from five young ( 3 months) and six aged (14 months) rats ${ }^{26}$ were filtered by using MAFilter software ${ }^{27}$ for differentially expressed genes. Probes with a Welch's $t$-test $P$ value $<0.01$ and a Wilks' $\lambda$ score $>2$ were considered to be differentially expressed between young and senescent rats. Cluster analysis (Manhattan distance) of the identified 264 probes (Supplemental Table S1) in 11 samples was performed with Genesis. ${ }^{35}$ The position of the Cond3 probe is indicated.

cytokines IL-1 $\beta$ and tumor necrosis factor- $\alpha$, which are activated from their latent precursors by caspase cleavage, ${ }^{47,48}$ this might point to a more proinflammatory milieu in older livers. Gene ontology analyses using the AmiGO 2 online tools revealed significant enrichment of pathways of the regulation of apoptotic processes (gene ontology: 0042981). How far these mechanisms link to the support of transplanted cell expansion by GH needs further experimental proof. Yet, it seems clear that in older livers, hepatocyte transplants not only meet an unfavorable proliferative milieu, but in addition, for example, a proapoptotic and proinflammatory microenvironment, both contributing to prohibition of successful engraftment and repopulation.

To estimate the clinical relevance of our results, we had the opportunity to probe DNA microarrays with human liver samples from 3- and 62-year-old donors. Obtained data were analyzed by gene ontology enrichment analysis using the AmiGO 2 software tool, as described above. A total of 600 genes were identified as significantly and differentially expressed in the juvenile and senescent human liver. The gene ontology enrichment analysis of these genes revealed a total of 85 significantly enriched categories in biological processes, as shown in Figure 10. At least four of these were linked to cell proliferation, but additional pathways were linked to immunological, growth factor, and cytokine-regulated processes. In addition, associations for developmental and cell migration processes, besides others, were discovered. These data underline that differences in juvenile and senescent human livers might exist, like in rats as described above, which generate a hepatic microenvironment rather favoring repopulation of young than old host livers by transplanted hepatocytes irrespective of the age of the donor cells. Further studies are needed to specify these differences on the molecular level to improve the outcome of clinical hepatocyte transplantation.

\section{Discussion}

\section{Proliferation of Hepatocyte Transplants Is Blunted in Senescent Livers}

To improve the quality of donor transplants for hepatocyte transplantation, numerous protocols attempted to optimize isolation and storage conditions for human hepatocytes. ${ }^{3}$ Although the transplantation of hepatocytes derived from either young or elder donors into children with inborn errors of the urea cycle seemed to be successful to a certain extent, ${ }^{2,49}$ achievements of transplantation into aged patients are still discouraging, ${ }^{3}$ potentially indicating that the recipient (liver) might affect the success of cell transplantation. Therefore, we studied the performance of juvenile and senescent rat hepatocytes in vitro and in vivo after transplantation into livers of young and aged recipient rats. Juvenile and senescent hepatocytes displayed similar functional and proliferative features in culture and in vivo, indicating that these could not account for the failure to repopulate senescent host livers. With culture time progressing, the expression of cyclin D3 increased, which might indicate the blockade of proliferation in aging hepatocytes, as previously reported. ${ }^{13}$ This was corroborated by persisting cell numbers and the accumulation of $\mathrm{G}_{1}$-phase proteins indicative for an arrest in the $G_{1}$ phase after 8 days of culture.

Assuming that a rat liver harbors $3 \times 10^{8}$ hepatocytes, and that after hepatocyte transplantation into juvenile livers approximately $20 \%$ of cells in the host parenchyma (ie, $0.6 \times 10^{8}$ cells) were donor derived (Figure 2), their number increased by 12 -fold, starting from $5 \times 10^{6}$ transplanted cells. On the contrary, cell numbers decreased by $50 \%$ after transplantation into senescent animals taking an overall repopulation rate of approximately $1 \%$ (Figure 2) into account. This is contradictory to results from previous reports demonstrating the increase in the clonogenic potential of transplanted hepatocytes with the recipient age. ${ }^{50}$ Likewise, higher repopulation rates were observed using fetal as compared to adult liver cells. Interestingly, no treatment with retrorsine was necessary to provide the donor cells with a growth advantage, and cell competition accounted for the promotion of repopulation by fetal liver cells involving increased levels of activin A and p15INK4b in older 


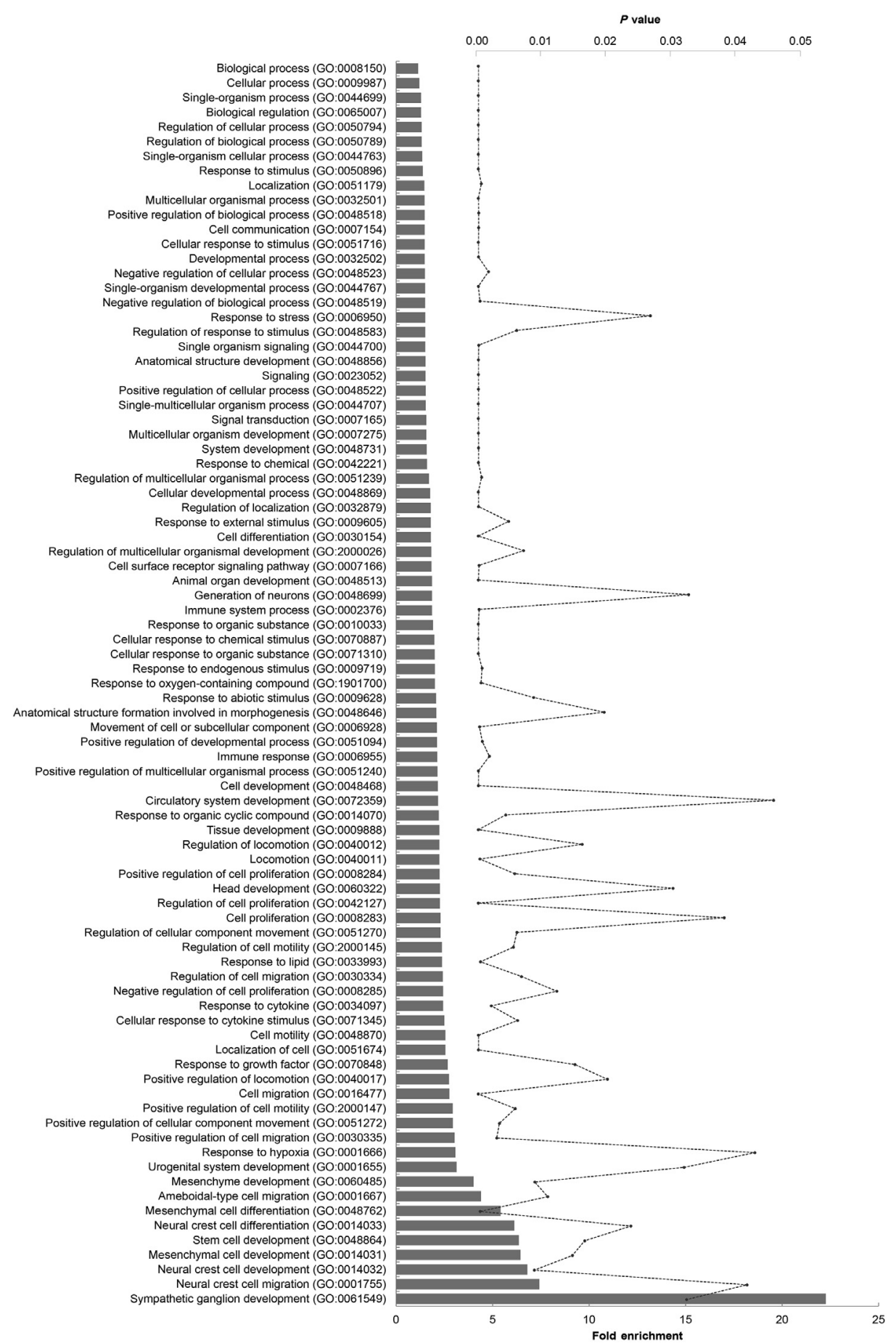

Figure 10 Gene ontology (G0) terms enriched from genes differentially expressed in human juvenile and senescent liver probes. A total of 85 biological processes were enriched from 600 genes (Supplemental Table S2) differentially expressed in the human liver probes. Analysis was performed as described in Materials and Methods. livers. ${ }^{51}$ Our data hence show that the repopulation potential of both juvenile and senescent donor hepatocytes is blunted in senescent recipient livers, suggesting a host-derived impact, which is supported by the global gene expression data suggesting that senescent livers might provide a more antiproliferative, proinflammatory, and proapoptotic microenvironment to transplanted hepatocytes than juvenile livers. This could generate an age-related decrease of the overall regenerative response after partial hepatectomy, ${ }^{10}$ which could be superimposed to hepatocytes transplanted into aged recipient livers.

\section{Growth Hormone Rescues Repopulation of Aged Livers by Transplanted Hepatocytes}

Cultured hepatocytes featured no age-related differences in the expression of the cell cycle proteins as far as investigated herein (Figure 5). Yet, expression of cell cycle 
proteins was significantly different in juvenile and senescent livers (Figure 8), indicating that these livers might provide different molecular environments for the repopulation by transplanted hepatocytes. It is known that liver regeneration was incomplete and that the rate of hepatocyte renewal was reduced in mice, which were deficient in $\mathrm{GH}$, suggesting a critical role of GH in liver regeneration. ${ }^{9}$ We detected lower $\mathrm{GH}$ serum levels in senescent than in juvenile host rats (Figure 6A), corroborating previous reports that $\mathrm{GH}$ decreased in mammals with increasing age. ${ }^{52}$ Knowing that $\mathrm{GH}$ is released into the circulation in a pulsatile manner with relatively high amplitudes, the presented data on GH means can only provide a rough estimate on the GH secretory stage. However, in combination with lower IGF-I concentrations in serum, which is the major pharmacodynamics marker of GH action, we are confident that the lower IGF-I in senescent rats (Supplemental Figure S2) is a consequence of reduced GH secretion. ${ }^{40}$ Because supplementation with rhGH could reconstitute GH levels, ${ }^{53}$ we assumed that low circulating $\mathrm{GH}$ might hamper repopulation of senescent livers. Indeed, senescent liver repopulation was significantly increased by rhGH substitution (Figure 7), which might involve cell cycle regulation by $\mathrm{GH}$. In the regenerating liver, GH was shown to eliminate the epigenetic silencing of E2F-responsive promoters by the destruction of the $\mathrm{C} / \mathrm{EBP} \alpha / \mathrm{Brahma} /$ histone deacetylase 1 complex via reducing cyclin $\mathrm{D} 3$, which is critical for the maintenance of the complex. ${ }^{13}$ In accordance with the regulation of cell cycle progression by $\mathrm{GH}$, factors involved in cell cycle pausing, like $\mathrm{C} / \mathrm{EBP} \alpha$, retinoblastoma, and cyclin $\mathrm{D} 3$, were elevated in senescent host livers and those involved in re-entering the cell cycle, like protein phosphatase 2A, PCNA, and cyclin D1, were decreased (Figure 8). The expression of these proteins in senescent livers was increased to levels comparable to juvenile livers by $\mathrm{GH}$ treatment, supporting the assumption that cell cycle regulation by $\mathrm{GH}$ was a key mechanism triggering the repopulation with transplanted hepatocytes. Others might contribute as our gene microarray analyses suggest.

It is reported that the treatment of recipient animals with retrorsine induces senescence in host hepatocytes, thus providing the donor hepatocytes with a growth advantage in the mitogenic environment after partial hepatectomy. ${ }^{16}$ Yet, we did not observe any significant difference in either the metabolic or the proliferative capacity of juvenile and senescent donor hepatocytes, substantiating the host liverderived impact on repopulation efficiency. Thus, it seems unlikely that cell senescence associated with pausing of cell cycle progression was induced by retrorsine treatment in juvenile animals. It seems rather likely that $\mathrm{GH}$ might overcome the inhibitory impact by retrorsine. This is naturally occurring in juvenile animals with sufficient high GH levels and might be induced in senescent animals by GH substitution. Along with the changes in cell cycle-related protein expression observed herein, this implies a molecular mechanism independent of growth inhibition by retrorsine, as described earlier. ${ }^{13,54,55}$ This is also supported by the finding that treatment of hepatocytes to be transplanted in advance with GH did not overcome failure of repopulation in senescent livers (Supplemental Figure S3), indicating a systemic and/or a contribution of the host liver.

In general, the impact of IGF-I is discussed controversially. It seems that liver-derived IGF-I might stimulate liver regeneration, but not directly growth of the intact liver. ${ }^{56}$ In line with this observation, IGF-I has been shown not to be a hepatocyte mitogen in vitro and no IGF-I receptor mRNA was detected during the first 24 hours after hepatectomy in regenerating liver cells. ${ }^{57}$ Thus, the improvement of senescent liver repopulation by transplanted hepatocytes is probably a direct effect of $\mathrm{GH}$ improving the unfavorable senescent to a juvenile mitotic host environment involving the onset of cell cycle progression by the mechanism, as described.

\section{Clinical Implications of Host Preconditioning for Hepatocyte Transplantation}

The impact of the host age on the effectiveness of immune cell transplantation was described earlier, showing that stem cell lines from old immunodeficient donors gave normal responses in young recipients. ${ }^{58}$ Similarly, interindividual transplantation of muscles between young and old rats revealed that organ recovery depended on the host age, leading to the conclusion that the poor regeneration of muscles in old animals was because of malfunctions of the recipient tissue environment. ${ }^{59}$ This is concordant with the results presented herein, which imply that treatment with GH might improve the regenerative capacity of the recipient liver. In line, hepatocellular functions recovered faster in patients receiving a living donor liver transplant than in the donors, which was because of higher GH serum levels in the recipients than in the donors. ${ }^{60}$ In urokinase-type plasminogen activator/severe combined immunodeficiency mice, long-term treatment with rhGH for up to 10 weeks stimulated the proliferation of human hepatocyte transplants. ${ }^{61}$ However, in the clinics, the long-term use of GH is inappropriate because of its hazardous adverse effects in the adult patient. ${ }^{44,45}$ It stimulated DNA synthesis in young and old livers without any surgery to a degree, as observed in young mice after partial hepatectomy. Thus, a mitotic stimulus induced by partial hepatectomy seemed dispensable in case of mitotic stimulation with GH. ${ }^{62}$ Hence, it was suggested that short-term GH treatment might be sufficient to support regeneration after liver transplantation, gene or cell therapy, or for rapid recovery after hepatic failure. ${ }^{63}$ The data presented herein are in line with this proposal. We may conclude that the poor repopulation efficiencies of aged host livers result, at least in part, from cell cycle pausing, which might be resolved by short-term treatment with $\mathrm{GH}$ restoring the juvenile molecular environment required for successful liver repopulation. Eventually, this could be a 
translational approach to improve clinical hepatocyte transplantation.

\section{Acknowledgments}

We thank Dr. Sandra Brückner, Dr. Sandra Winkler (University of Leipzig), and Prof. Dr. Matthias Dollinger (University of Ulm, Germany) for helpful suggestions; Madlen Hempel (University of Leipzig), Amon Horngacher (University Clinic Munich), and Ines Volkmer (Martin Luther University Halle-Wittenberg) for excellent technical assistance; and Prof. S.C. Strom (Karolinska Institutet formerly University of Pittsburgh) for liver tissue samples.

P.S. performed experiments, analyzed data, designed the studies, and wrote the manuscript; Max.B. and Mar.B. performed experiments, wrote the manuscript, and analyzed data; M.S.S. performed experiments, wrote parts of the manuscript, and analyzed data; M.-J.H. performed experiments, wrote parts of the manuscript, and analyzed data; B.C. designed the studies, analyzed data, and wrote the manuscript. All authors read and commented on the manuscript.

\section{Supplemental Data}

Supplemental material for this article can be found at http://dx.doi.org/10.1016/j.ajpath.2016.11.016.

\section{References}

1. Mazariegos G, Shneider B, Burton B, Fox IJ, Hadzic N, Kishnani P, Morton DH, McIntire S, Sokol RJ, Summar M, White D, Chavanon V, Vockley J: Liver transplantation for pediatric metabolic disease. Mol Genet Metab 2014, 111:418-427

2. Dhawan A: Clinical human hepatocyte transplantation: current status and challenges. Liver Transpl 2015, 21(Suppl 1):S39-S44

3. Hansel MC, Gramignoli R, Skvorak KJ, Dorko K, Marongiu F, Blake W, Davila J, Strom SC: The history and use of human hepatocytes for the treatment of liver diseases: the first 100 patients. Curr Protoc Toxicol 2014, 62:14.12.1-14.12.23

4. Forbes SJ, Gupta S, Dhawan A: Cell therapy for liver disease: from liver transplantation to cell factory. J Hepatol 2015, 62(1 Suppl): S157-S169

5. Walldorf J, Aurich H, Cai H, Runge D, Christ B, Strom SC, Fleig WE: Expanding hepatocytes in vitro before cell transplantation: donor age-dependent proliferative capacity of cultured human hepatocytes. Scand J Gastroenterol 2004, 39:584-593

6. Schmucker DL: Age-related changes in liver structure and function: implications for disease? Exp Gerontol 2005, 40(8-9):650-659

7. Borchert D, Glanemann M, Mogl M, Langrehr JM, Neuhaus P: Older liver graft transplantation, cholestasis and synthetic graft function. Transpl Int 2005, 18:709-715

8. Michalopoulos GK: Liver regeneration after partial hepatectomy: critical analysis of mechanistic dilemmas. Am J Pathol 2010, 176: $2-13$

9. Pennisi PA, Kopchick JJ, Thorgeirsson S, LeRoith D, Yakar S: Role of growth hormone $(\mathrm{GH})$ in liver regeneration. Endocrinology 2004, $145: 4748-4755$

10. Sanchez-Hidalgo JM, Naranjo A, Ciria R, Ranchal I, AguilarMelero P, Ferrin G, Valverde A, Rufian S, Lopez-Cillero P,
Muntane J, Briceno J: Impact of age on liver regeneration response to injury after partial hepatectomy in a rat model. J Surg Res 2012, 175: $\mathrm{e} 1-\mathrm{e} 9$

11. Collin de l'Hortet A, Zerrad-Saadi A, Prip-Buus C, Fauveau V, Helmy N, Ziol M, Vons C, Billot K, Baud V, Gilgenkrantz H, Guidotti JE: GH administration rescues fatty liver regeneration impairment by restoring GH/EGFR pathway deficiency. Endocrinology 2014, 155:2545-2554

12. Conboy IM, Conboy MJ, Wagers AJ, Girma ER, Weissman IL, Rando TA: Rejuvenation of aged progenitor cells by exposure to a young systemic environment. Nature 2005, 433:760-764

13. Timchenko NA: Aging and liver regeneration. Trends Endocrinol Metab 2009, 20:171-176

14. Koenig S, Stoesser C, Krause P, Becker H, Markus PM: Liver repopulation after hepatocellular transplantation: integration and interaction of transplanted hepatocytes in the host. Cell Transplant 2005, 14:31-40

15. Serra MP, Marongiu F, Marongiu M, Contini A, Laconi E: Cellautonomous decrease in proliferative competitiveness of the aged hepatocyte. J Hepatol 2015, 62:1341-1348

16. Serra MP, Marongiu F, Sini M, Laconi E: Hepatocyte senescence in vivo following preconditioning for liver repopulation. Hepatology 2012, 56:760-768

17. Thompson NL, Hixson DC, Callanan H, Panzica M, Flanagan D, Faris RA, Hong WJ, Hartel-Schenk S, Doyle D: A Fischer rat substrain deficient in dipeptidyl peptidase IV activity makes normal steady-state RNA levels and an altered protein: use as a liver-cell transplantation model. Biochem J 1991, 273(Pt 3):497-502

18. Seglen PO: Preparation of isolated rat liver cells. Methods Cell Biol 1976, 13:29-83

19. Stock P: Age-dependent hepatocyte transplantation for functional liver tissue reconstitution. Methods Mol Biol 2014, 1213:41-50

20. Runge D, Kohler C, Kostrubsky VE, Jager D, Lehmann T, Runge DM, May U, Stolz DB, Strom SC, Fleig WE, Michalopoulos GK: Induction of cytochrome P450 (CYP)1A1, CYP1A2, and CYP3A4 but not of CYP2C9, CYP2C19, multidrug resistance (MDR-1) and multidrug resistance associated protein (MRP-1) by prototypical inducers in human hepatocytes. Biochem Biophys Res Commun 2000, 273:333-341

21. Laconi E, Oren R, Mukhopadhyay DK, Hurston E, Laconi S, Pani P, Dabeva MD, Shafritz DA: Long-term, near-total liver replacement by transplantation of isolated hepatocytes in rats treated with retrorsine. Am J Pathol 1998, 153:319-329

22. Fashe MM, Juvonen RO, Petsalo A, Rahnasto-Rilla M, Auriola S, Soininen P, Vepsalainen J, Pasanen M: Identification of a new reactive metabolite of pyrrolizidine alkaloid retrorsine: (3H-pyrrolizin-7-yl)methanol. Chem Res Toxicol 2014, 27: $1950-1957$

23. Fashe MM, Juvonen RO, Petsalo A, Vepsalainen J, Pasanen M, Rahnasto-Rilla M: In silico prediction of the site of oxidation by cytochrome P450 3A4 that leads to the formation of the toxic metabolites of pyrrolizidine alkaloids. Chem Res Toxicol 2015, 28: 702-710

24. Ruan J, Yang M, Fu P, Ye Y, Lin G: Metabolic activation of pyr rolizidine alkaloids: insights into the structural and enzymatic basis. Chem Res Toxicol 2014, 27:1030-1039

25. Wang X, Tang Y, Lu J, Shao Y, Qin X, Li Y, Wang L, Li D, Liu M: Characterization of novel cytochrome P450 2E1 knockout rat model generated by CRISPR/Cas9. Biochem Pharmacol 2016, 105:80-90

26. Oszkiel H, Wilczak J, Jank M: Biologically active substances: enriched diet regulates gonadotrope cell activation pathway in liver of adult and old rats. Genes Nutr 2014, 9:427

27. Winkler C, Steingrube DS, Altermann W, Schlaf G, Max D, Kewitz S, Emmer A, Kornhuber M, Banning-Eichenseer U, Staege MS: Hodgkin's lymphoma RNA-transfected dendritic cells induce cancer/testis antigen-specific immune responses. Cancer Immunol Immunother 2012, 61:1769-1779 
28. Stock P, Staege MS, Muller LP, Sgodda M, Volker A, Volkmer I, Lutzkendorf J, Christ B: Hepatocytes derived from adult stem cells. Transplant Proc 2008, 40:620-623

29. Mootha VK, Lindgren CM, Eriksson KF, Subramanian A, Sihag S, Lehar J, Puigserver P, Carlsson E, Ridderstrale M, Laurila E, Houstis N, Daly MJ, Patterson N, Mesirov JP, Golub TR, Tamayo P, Spiegelman B, Lander ES, Hirschhorn JN, Altshuler D, Groop LC: PGC-1alpha-responsive genes involved in oxidative phosphorylation are coordinately downregulated in human diabetes. Nat Genet 2003, $34: 267-273$

30. Subramanian A, Tamayo P, Mootha VK, Mukherjee S, Ebert BL, Gillette MA, Paulovich A, Pomeroy SL, Golub TR, Lander ES, Mesirov JP: Gene set enrichment analysis: a knowledge-based approach for interpreting genome-wide expression profiles. Proc Natl Acad Sci U S A 2005, 102:15545-15550

31. Ashburner M, Ball CA, Blake JA, Botstein D, Butler H, Cherry JM, Davis AP, Dolinski K, Dwight SS, Eppig JT, Harris MA, Hill DP, Issel-Tarver L, Kasarskis A, Lewis S, Matese JC, Richardson JE, Ringwald M, Rubin GM, Sherlock G: The Gene Ontology Consortium: Gene ontology: tool for the unification of biology. Nat Genet 2000, 25:25-29

32. Carbon S, Ireland A, Mungall CJ, Shu S, Marshall B, Lewis S; AmiGO Hub; Web Presence Working Group: AmiGO: online access to ontology and annotation data. Bioinformatics 2009, 25:288-289

33. Gene Ontology Consortium: Gene Ontology Consortium: going forward. Nucleic Acids Res 2015, 43(Database issue):D1049-D1056

34. Gene Ontology Consortium, Blake JA, Dolan M, Drabkin H, Hill DP, Li N, Sitnikov D, et al: Gene Ontology annotations and resources. Nucleic Acids Res 2013, 41(Database issue):D530-D535

35. Sturn A, Quackenbush J, Trajanoski Z: Genesis: cluster analysis of microarray data. Bioinformatics 2002, 18:207-208

36. Laemmli UK: Cleavage of structural proteins during the assembly of the head of bacteriophage T4. Nature 1970, 227:680-685

37. Timm F, Vollmar B: Heterogeneity of the intrahepatic portal venous blood flow: impact on hepatocyte transplantation. Microvasc Res 2013, 86:34-41

38. Chapman IM, Helfgott A, Willoughby JO: Disappearance half-life times of exogenous and growth hormone-releasing factor-stimulated endogenous growth hormone in normal rats. J Endocrinol 1991, 128 : 369-374

39. Thangavel C, Dworakowski W, Shapiro BH: Inducibility of malespecific isoforms of cytochrome p450 by sex-dependent growth hormone profiles in hepatocyte cultures from male but not female rats. Drug Metab Dispos 2006, 34:410-419

40. Bielohuby M, Schaab M, Kummann M, Sawitzky M, Gebhardt R, Binder G, Frystyk J, Bjerre M, Hoeflich A, Kratzsch J, Bidlingmaier M: Serum IGF-I is not a reliable pharmacodynamic marker of exogenous growth hormone activity in mice. Endocrinology 2011, 152:4764-4776

41. Veldhuis JD, Bidlingmaier M, Anderson SM, Evans WS, Wu Z, Strasburger CJ: Impact of experimental blockade of peripheral growth hormone $(\mathrm{GH})$ receptors on the kinetics of endogenous and exogenous GH removal in healthy women and men. J Clin Endocrinol Metab 2002, 87:5737-5745

42. Fu PP, Xia Q, Lin G, Chou MW: Pyrrolizidine alkaloids: genotoxicity, metabolism enzymes, metabolic activation, and mechanisms. Drug Metab Rev 2004, 36:1-55

43. Koenig S, Aurich H, Schneider C, Krause P, Haftendorn R, Becker H, Christ B: Zonal expression of hepatocytic marker enzymes during liver repopulation. Histochem Cell Biol 2007, 128:105-114

44. Diaz ME, Miquet JG, Rossi SP, Irene PE, Sotelo AI, Frungieri MB, Turyn D, Gonzalez L: GH administration patterns differently regulate epidermal growth factor signaling. J Endocrinol 2014, 221:317-323
45. Navarro R, Dunn JD, Lee PA, Owens GM, Rapaport R: Translating clinical guidelines into practice: the effective and appropriate use of human growth hormone. Am J Manag Care 2013, 19(15 Suppl): s281-s289

46. van Oijen MG, Medema RH, Slootweg PJ, Rijksen G: Positivity of the proliferation marker Ki-67 in noncycling cells. Am J Clin Pathol 1998, 110:24-31

47. Rothlein R, Dustin ML, Marlin SD, Springer TA: A human intercellular adhesion molecule (ICAM-1) distinct from LFA-1. J Immunol 1986, 137:1270-1274

48. Yang L, Froio RM, Sciuto TE, Dvorak AM, Alon R, Luscinskas FW: ICAM-1 regulates neutrophil adhesion and transcellular migration of TNF-alpha-activated vascular endothelium under flow. Blood 2005, 106:584-592

49. Meyburg J, Das AM, Hoerster F, Lindner M, Kriegbaum H, Engelmann G, Schmidt J, Ott M, Pettenazzo A, Luecke T, Bertram H, Hoffmann GF, Burlina A: One liver for four children: first clinical series of liver cell transplantation for severe neonatal urea cycle defects. Transplantation 2009, 87:636-641

50. Pasciu D, Montisci S, Greco M, Doratiotto S, Pitzalis S, Pani P, Laconi S, Laconi E: Aging is associated with increased clonogenic potential in rat liver in vivo. Aging Cell 2006, 5:373-377

51. Menthena A, Koehler CI, Sandhu JS, Yovchev MI, Hurston E, Shafritz DA, Oertel M: Activin A, p15INK4b signaling, and cell competition promote stem/progenitor cell repopulation of livers in aging rats. Gastroenterology 2011, 140:1009-1020

52. Bielohuby M, Popp S, Bidlingmaier M: Influence of pre-analytical conditions on the measurement of components of the GH/IGF axis in rats. Growth Horm IGF Res 2013, 23:141-148

53. Velasco B, Cacicedo L, Melian E, Fernandez-Vazquez G, SanchezFranco F: Sensitivity to exogenous GH and reversibility of the reduced IGF-I gene expression in aging rats. Eur J Endocrinol 2001, $145: 73-85$

54. Johnson PF: Molecular stop signs: regulation of cell-cycle arrest by C/EBP transcription factors. J Cell Sci 2005, 118(Pt 12):2545-2555

55. Alison MR, Marongiu F, Laconi E: Transplanted hepatocytes: wiped out or washed out? J Hepatol 2012, 56:996-997

56. Ohlsson C, Mohan S, Sjogren K, Tivesten A, Isgaard J, Isaksson O, Jansson JO, Svensson J: The role of liver-derived insulin-like growth factor-I. Endocr Rev 2009, 30:494-535

57. Mohn KL, Melby AE, Tewari DS, Laz TM, Taub R: The gene encoding rat insulinlike growth factor-binding protein 1 is rapidly and highly induced in regenerating liver. Mol Cell Biol 1991, 11: 1393-1401

58. Harrison DE, Astle CM, Doubleday JW: Cell lines from old immunodeficient donors give normal responses in young recipients. J Immunol 1977, 118:1223-1227

59. Carlson BM, Faulkner JA: Muscle transplantation between young and old rats: age of host determines recovery. Am J Physiol 1989, 256(6 Pt 1):C1262-C1266

60. Jara M, Schulz A, Malinowski M, Puhl G, Lock JF, Seehofer D, Neuhaus P, Stockmann M: Growth hormone/insulin-like growth factor 1 dynamics in adult living donor liver transplantation. Liver Transpl 2014, 20:1118-1126

61. Masumoto N, Tateno C, Tachibana A, Utoh R, Morikawa Y, Shimada T, Momisako H, Itamoto T, Asahara T, Yoshizato K: GH enhances proliferation of human hepatocytes grafted into immunodeficient mice with damaged liver. J Endocrinol 2007, 194:529-537

62. Krupczak-Hollis K, Wang X, Dennewitz MB, Costa RH: Growth hormone stimulates proliferation of old-aged regenerating liver through forkhead box m1b. Hepatology 2003, 38:1552-1562

63. Mackey S, Singh P, Darlington GJ: Making the liver young again. Hepatology 2003, 38:1349-1352 